\title{
DANI EJZENBERG
}

\section{Avaliação histomorfométrica do endométrio na fase lútea de mulheres férteis e inférteis}

\author{
Tese apresentada à Faculdade de Medicina da \\ Universidade de São Paulo para a obtenção do título \\ de Doutor em Ciências
}

Programa de Obstetrícia e Ginecologia Orientador: Prof. Dr. Paulo Cesar Serafini

São Paulo

2012 
Dados Internacionais de Catalogação na Publicação (CIP)

Preparada pela Biblioteca da

Faculdade de Medicina da Universidade de São Paulo

Creprodução autorizada pelo autor

\section{Ejzenberg, Dani}

Avaliação histomorfométrica do endométrio na fase lútea de mulheres férteis e inférteis / Dani Ejzenberg. -- São Paulo, 2012.

Tese(doutorado)--Faculdade de Medicina da Universidade de São Paulo.

Programa de Obstetrícia e Ginecologia.

Orientador: Paulo Cesar Serafini.

Descritores: 1.Infertilidade 2.Implantação do embrião 3.Endométrio/anatomia \& histologia 4.Histeroscopia 5.Biópsia/métodos

USP/FM/DBD-227/12 


\section{Dedicatória}

Dedico esta tese à minha esposa Daniela e ao meu filho Davi. Este projeto não é apenas uma conquista pessoal, mas de toda a família.

Daniela é companheira de todos os momentos, mãe exemplar, profissional competente e grande incentivadora do meu desenvolvimento profissional e acadêmico. Estas poucas linhas são insuficientes para expressar todo afeto e admiração que sinto por ela.

Davi com seu sorriso encantador é fonte de muitas alegrias e como pequeno desbravador causador de alguns sobressaltos. Trouxe também amadurecimento e novos objetivos para a família. Espero que no futuro você compreenda a ausência do seu pai em algumas brincadeiras e passeios. 


\section{Agradecimento Especial}

Ao meu orientador Prof. Paulo Serafini que é exemplo de dedicação ao trabalho e aos seus pacientes, que atingiu o sucesso como médico e pesquisador no Brasil e nos EUA, e que com seus comentários e sugestões permitiu grande aprimoramento desta pesquisa. 


\section{Agradecimentos}

Ao Prof. Edmund Chada Baracat pela confiança depositada, pelas sugestões para o aperfeiçoamento desta pesquisa e pelo estímulo constante na busca da pesquisa ética e de qualidade.

Ao Prof. Manuel Simões pela calorosa acolhida em seu laboratório no Departamento de Morfologia e Genética da UNIFESP-EPM, pela análise histológica das amostras e supervisão da análise morfométrica.

Ao Dr. Walter Pinheiro pelo auxilio na obtenção dos materiais e infraestrutura que possibilitaram este estudo, pelo apoio e estímulo constantes, pela confiança depositada e pelo companheirismo em todos os momentos.

Ao Dr. Aloísio Felipe Souza da Silva e Dra. Lidiane Marins pela disponibilidade em meio à rotina sobrecarregada e pela cuidadosa análise histopatológica das amostras.

À pós-graduanda Adriana Ferraz Carbonell pelo auxílio e paciência nas longas jornadas para realizar a análise morfométrica das amostras.

Ao técnico de laboratório e pós graduando da UNIFESP Paulo Cesar Franco pela persistência e precisão no processamento das amostras. 
Às pacientes participantes que permitiram a realização deste estudo.

À Strattner do Brasil pelo fornecimento de parte dos materiais indispensáveis para realização deste estudo.

À auxiliar de enfermagem Érica dos Santos pelo auxílio na montagem da sala e durante os exames histeroscópicos.

À Enfermeira Cristina Miyuki Origassa e Auxiliar de Enfermagem Andrea Cristina Moraes Cardoso pelo auxílio na triagem e convocação das pacientes participantes deste estudo.

À Dra Creusa Maria Roveri Dal Bó pela extensa análise estatística dos dados apresentados.

À Dra Roseli Ejzenberg pela revisão do resumo em inglês.

Aos Drs. Élvio Tognotti, Pedro Monteleone, Marcello Coccuzza, Rodrigo Pagani, Claudia Messias Gomes, Paula Fettback, Gustavo Kroger, Paulo Bianchi, Oscar Barbosa Duarte Filho, Lucas Yamakami, Eduardo Myadahira, Rodrigo José, e todos os demais colegas do Centro de Reprodução Humana pela compreensão no meu envolvimento neste projeto. 
Aos meus pais Vânia e Bernardo, fontes inesgotáveis de carinho, amizade, cuidados, ensinamentos e dedicação. Parceiros importantes de todas as vitórias e exemplos para todos que os cercam.

À minha irmã Priscila e meu cunhado Fábio pelo apoio e incentivo constantes e por terem trazido ao mundo o meu simpático e querido sobrinho Beni.

Aos meus avós, Rosa Guinsburg, Helena e Izrael Ejzenberg (in memoriam) pelo afeto, apoio e ensinamentos desde a infância.

Ao meu sogro Claudio Bin pelo interesse e apoio sempre presentes.

Aos meus colegas de panela pela amizade e estímulo para o desenvolvimento acadêmico.

Á Sras. Claudia Vieira e Cristiane Rodrigues do Amaral pela colaboração na revisão de formato desta tese.

Á Sras. Célia Conceição Morais, Mara Núbia, Sonia Regina Rodrigues e Srs. Moacir Lopes e Leslie Santos por sua valiosa colaboração nas atividades cotidianas. 
NORMALIZAÇÃO ADOTADA

Esta dissertação está de acordo com as seguintes normas, em vigor no momento desta publicação:

REFERÊNCIAS: ADAPTADAS DE INTERNATIONAL COMMITEE OF MEDICAL JOURNALS EDITORS (VANCOUVER)

UNIVERSIDADE DE SÃO PAULO. FACULDADE DE MEDICINA. SERVIÇO DE BIBLIOTECA E DOCUMENTAÇÃO. GUIA DE APRESENTAÇÃO DE DISSERTAÇÕES, TESES E MONOGRAFIAS. ELABORADO POR ANNELIESE CARNEIRO DA CUNHA, MARIA JULIA DE A. L. FREDDI, MARIA F. CRESTANA, MARINALVA DE SOUZA ARAGÃO, SUELY CAMPOS CARDOSO, VALÉRIA VILHENA. SÃO PAULO: SERVIÇO DE BIBLIOTECA E DOCUMENTAÇÃO; 2005

ABREVIATURAS DOS TÍTULOS DOS PERIÓDICOS DE ACORDO COM LIST OF JOURNALS INDEXED IN INDEX MEDICUS 


\section{SUMÁRIO}

Lista de abreviaturas

Lista de tabelas

Lista das figuras

Lista de anexos

Resumo

Summary

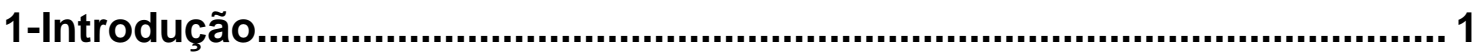

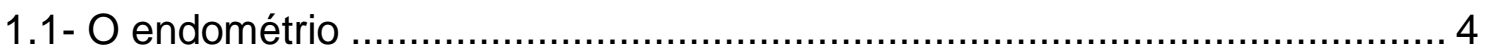

1.2- O endométrio na fase de implantação .................................................. 4

1.3- Técnicas de biópsia endometrial ........................................................ 6

1.4- Indicações da biopsia endometrial .................................................. 7

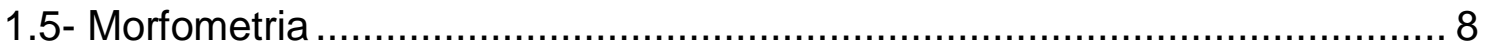

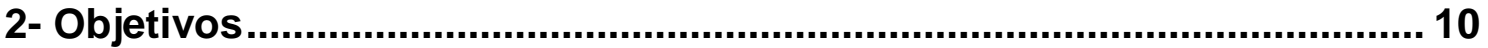

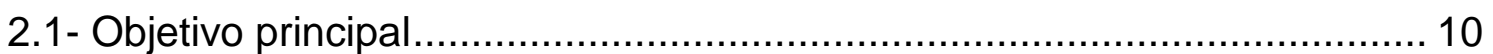

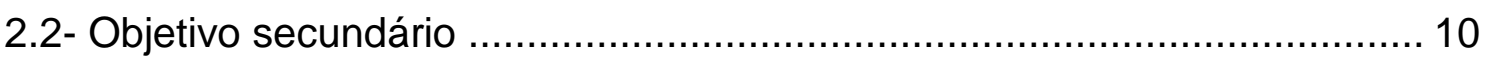

3- Métodos ..................................................................................................... 11

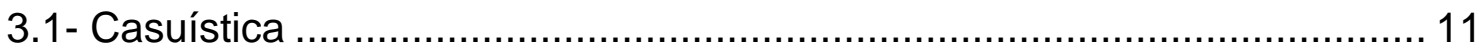

3.2- Procedimentos .............................................................................. 12

3.3- Processamento do material............................................................... 14

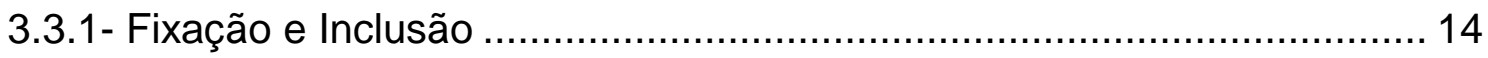

3.3.2- Microtomia ................................................................................ 14

3.3.3- Métodos de coloração ............................................................... 14

3.4- Análise Morfométrica .................................................................... 14

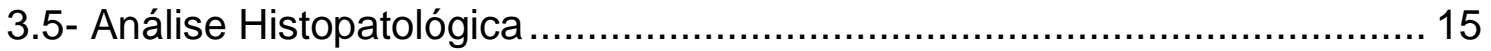

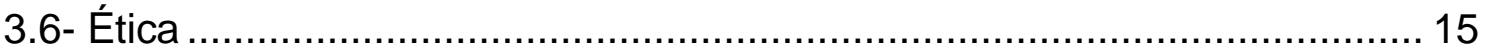

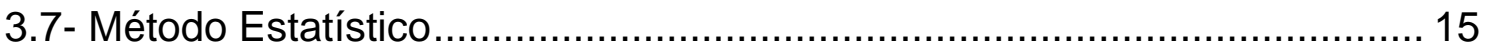

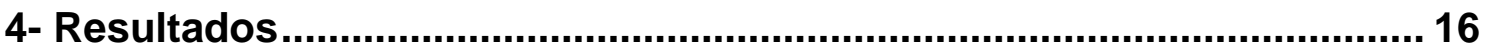

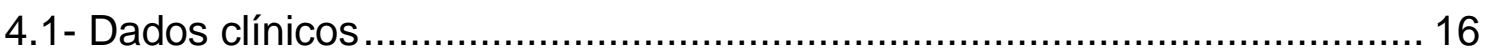

4.2- Data do exame ............................................................................ 17

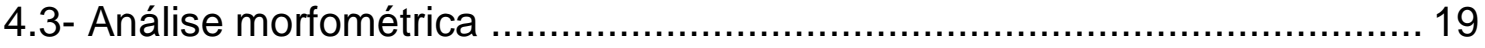




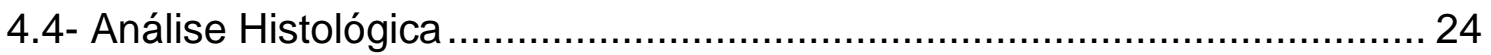

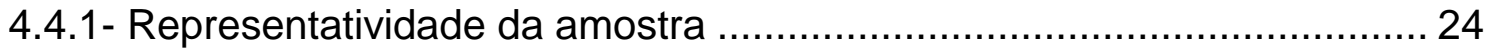

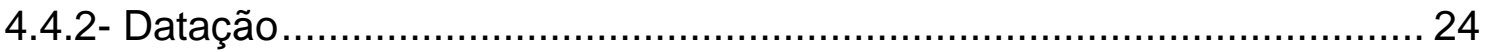

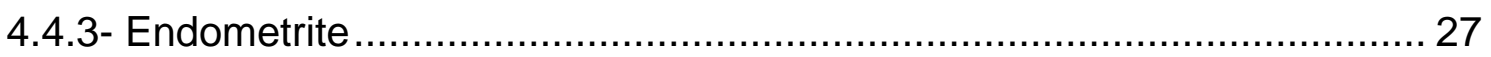

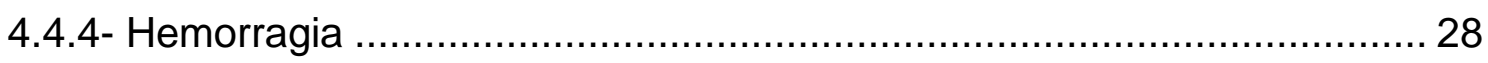

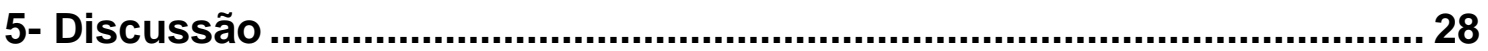

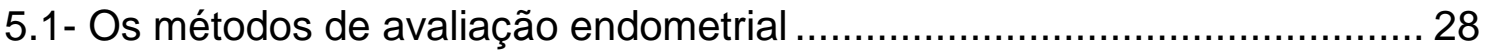

5.2- $O$ endométrio da paciente fértil $X$ endométrio paciente infértil .................. 30

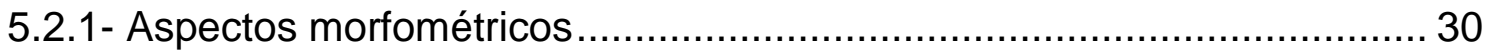

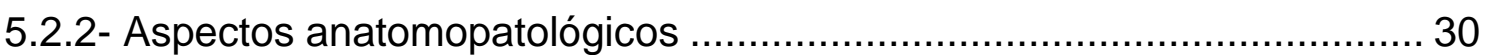

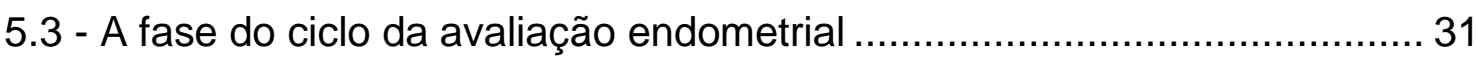

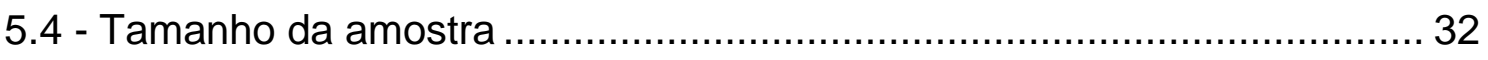

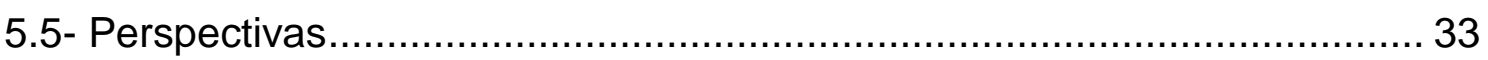

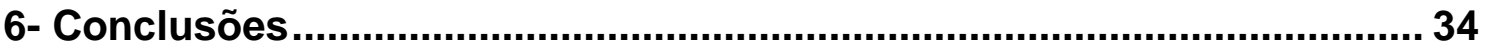

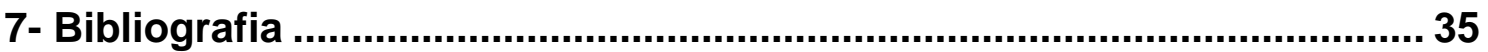

8- Anexos 


\section{LISTA DE ABREVIATURAS}

FIV- fertilização in vitro

OMS- Organização Mundial da Saúde

DIP- doença inflamatória pélvica

HE- Hematoxilina e eosina

USP- Universidade de São Paulo

UNIFESP- Universidade Federal de São Paulo

$\mu$ m- micrômetro 


\section{LISTA DE TABELAS}

Tabela 1: Idade das pacientes dos grupos controle e infértil 17

Tabela 2: Idade das pacientes do grupo controle e subgrupos inférteis 17

Tabela 3: Intervalo (em dias) entre o início do ciclo menstrual e a realização da histeroscopia no grupo controle e no grupo infértil 18

Tabela 4: Intervalo (em dias) entre o início do ciclo menstrual e a realização da histeroscopia no grupo controle e subgrupos inférteis 18

Tabela 5: Espessura do epitélio superficial $(\mu \mathrm{m})$ das parede uterinas anterior (PA) e posterior (PP) e na biópsia aspirativa (ASP)

Tabela 6: Espessura do epitélio superficial $(\mu \mathrm{m})$ das paredes uterinas anterior, posterior, e na biópsia aspirativa, nos grupos infértil e controle

Tabela 7: Espessura do epitélio superficial $(\mu \mathrm{m})$, da parede uterina anterior, posterior, e na biópsia aspirativa, subgrupos inférteis e controle

Tabela 8: Área circular das glândulas endometriais obtida por biópsia dirigida em dois sítios uterinos e por aspiração (médias $\mu m^{2}$ ).

Tabela 9: Área circular das glândulas endometriais nas paredes uterinas, nos grupos controle e infértil (médias $\mu \mathrm{m}^{2}$ ).

Tabela 10: Altura celular na glândula endometrial $(\mu \mathrm{m})$ de todos os casos, obtida por biópsia dirigida em dois sítios uterinos e por aspiração

Tabela 11: Altura celular na glândula endometrial $(\mu \mathrm{m})$ obtida por biópsia dirigida em dois sítios uterinos e por biópsia aspirativa (médias $\mu \mathrm{m}^{2}$ )

Tabela 12: Número de glândulas por biópsia dirigida em dois sítios uterinos e por biópsia aspirativa

Tabela 13: Resultados da datação (em dias) do endométrio na parede anterior e posterior , e por biópsia aspirativa. 
Tabela 14: Resultados da datação (em dias) do endométrio segundo local de coleta e a fertilidade

Tabela 15: Resultados da datação (em dias) do endométrio segundo local de coleta e o tipo de infertilidade.

Tabela 16: Homogeneidade na datação de fase menstrual no grupo controle e subgrupos inférteis, critérios histológicos de Noyes. 


\section{LISTA DE FIGURAS}

Figura 1- Foto e esquema da cavidade uterina e pontos de biópsia.

Figura 2- Esquema para ilustrar a histeroscopia diagnóstica com equipamento

de Bettocchi ${ }^{\circledR}$

Figura 3- Instrumental para histeroscopia diagnóstica com_Equipamento de

Bettocchi $^{\circledR}$

Figura 4- Imagem de biópsia aspirativa com hemorragia no estroma

endometrial grupo controle férti

Figuras 5 e 6- Imagem de biópsia dirigida do grupo controle fértil com estroma

preservado 45

\section{LISTA DE ANEXOS}

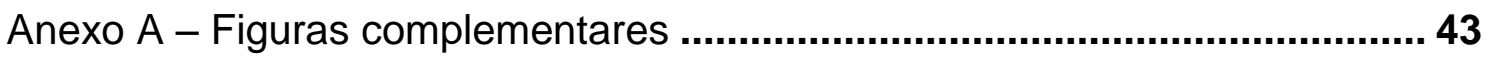

Anexo B- TERMO DE CONSENTIMENTO LIVRE E ESCLARECIDO .............. 45

Anexo C- Aprovação do Comitê de Ética …................................................... 50 


\section{RESUMO}

Ejzenberg D. Avaliação histomorfométrica do endométrio na fase lútea de mulheres férteis e inférteis [tese]. São Paulo: Faculdade de Medicina, Universidade de São Paulo; 2012.

OBJETIVO: avaliar a histomorfometria do endométrio na fase lútea de mulheres férteis e inférteis. MÉTODOS: foram triadas 40 pacientes, 30 inférteis e 10 férteis, em seguimento na Clínica Ginecológica do HC-FMUSP, que concordaram em participar deste estudo. Foi realizada avaliação ultrassonográfica seriada a partir da menstruação, para determinação da ovulação. Na fase lútea as pacientes eram submetidas à histeroscopia. Foram excluídas 14 pacientes sendo 12 por falta durante a avaliação ultrassonográfica e 2 pela presença de pólipos. A casuística foi composta por 6 controles férteis, que foram comparadas a 20 casos inférteis (endometriose-8, causa tuboperitoneal-5, causa masculina-5, sem causa aparente-2). Na histeroscopia foram coletadas duas biópsias dirigidas (sistema de Bettocchi) da parede posterior (terço distal), e da parede anterior (terço médio), e uma biópsia aspirativa com Pipelle. Foram avaliados parâmetros histomorfométricos endometriais. RESULTADOS: as duas formas de biópsia foram apropriadas para análise endometrial; a dirigida coletou menor área tecidual, porém sem sangue. Nenhum paciente fértil apresentou heterogeneidade endometrial (atraso de fase em algum sítio); isto ocorreu em 7 (35\%) das inférteis ( $p=0,11)$. Foi diagnosticada endometrite em $2(10 \%)$ casos. CONCLUSÃO: não foram observadas diferenças histomorfométricas entre o endométrio de mulheres férteis e inférteis na fase lútea. Parte das pacientes inférteis mostrou heterogeneidade endometrial e endometrite. A biópsia dirigida, assim como a aspirativa, foi adequada ao estudo endometrial na fase lútea.

Descritores: infertilidade, endométrio, implantação embrionária, histeroscopia, biópsia 


\section{SUMMARY}

Objective: to evaluate the endometrial histomorphometry of fertile and infertile women during their luteal period. Methods: 40 female patients- 30 infertile and 10 fertile- who were being followed-up at the Gynecological Clinic at the Hospital das Clinicas (HC),-Faculdade de Medicina da Universidade de Sa $\square$ o Paulo (FMUSP), agreed to participate in the study. Serial ultra sonograms, starting from their menstrual period, were performed to identify their ovulation. In the luteal phase the patients underwent hysteroscopy. From the initial sample, 14 patients were excluded from the study, 12 of whom for being absent during scheduled ultra sonograms and 2 for presenting polyps. The final sample thus consisted of 6 fertile females (control subjects) who were compared to 20 patients with infertility, categorized as follows: 8 due to endometriosis, 5 due to peritoneal tube conditions, 5 due to male infertility, and 2 with no apparent cause. During the hysteroscopy 2 directed biopsies (Bettocchi's System) of the posterior wall (distal third section) and of the anterior wall (medial third) were performed, as well as Pipelle sampling. Endometrial histomorpholometric parameters were evaluated. Results: the two forms of endometrial sampling performed were appropriate for the endometrial analysis. The directed biopsy collected tissue from a smaller area, but it had no blood. None of the fertile patients presented endometrial heterogeneity, i.e., phase delay in any site. In contrast, this occurred in $7(35 \%)$ of the infertile females $(p=0.11)$. Endometritis was diagnosed in $2(10 \%)$ of the cases. Conclusions: no histomorphometric differences were observed in the endometrium of the fertile and infertile female patients during their luteal phase. About a third of infertile cases (35\%) displayed endometrial heterogeneity and a small percentage of which (10\%) had endometritis. Both the directed biopsy and Pipelle sampling were found satisfactory for studies of endometrium during the luteal phase.

Descriptors: infertility, endometrium, embryo implantation, hysteroscopy,biopsy 


\section{1-Introdução}

A infertilidade é uma condição clínica que transcende o âmbito conjugal e atinge a sociedade de forma ampla (WHO | Mother or nothing: the agony of infertility, 2010; Chachamovich, J. R., Chachamovich, E., Ezer, H., Fleck, M. P., Knauth, D. R. et al., 2010). Antes restrita apenas aos médicos e casais envolvidos, atualmente este tema esta presente nas redes sociais e fóruns de discussão cibernéticos (Kirkman, 2001). Mais recentemente, também se tornou uma preocupação individual, para uma parcela das jovens que desejam a procriação após um tratamento para câncer, ou como valor independente do matrimônio (Robinson, 1997; Yli-Kuha, Gissler et al., 2012). Para todos os envolvidos é frequente a ocorrência de infelicidade e muitas vezes de distúrbios psíquicos e sociais secundários. A ausência de filhos pode determinar depressão e ansiedade segundo alguns autores, assim como a piora no relacionamento conjugal, prejuízo da função sexual e redução dos índices de qualidade de vida (Chachamovich, J. L., Chachamovich, E. et al., 2010; Chachamovich, J. R., Chachamovich, E., Ezer, H., Fleck, M. P., Knauth, D. et al., 2010; Chachamovich, J. R., Chachamovich, E., Ezer, H., Fleck, M. P., Knauth, D. R. et al., 2010; Aarts, Huppelschoten et al., 2012). Para a sociedade ainda há os custos financeiros, determinados pela redução na capacidade de produção, pelos tratamentos médicos envolvidos, assim como a perda de riqueza que seria produzida pelos filhos não gerados (Connolly, Pollard et al., 2008; Connolly, Gallo et al., 2009; Kröger e Ejzenberg, 2012). No mundo contemporâneo, em que a Arte Médica logrou resolver ou minorar grande parte das moléstias e agravos, a importância da infertilidade é 
crescente, pois ainda é grande a parcela das mulheres que não conseguem engravidar mesmo com a utilização dos tratamentos mais modernos (Van Voorhis, 2006).

A infertilidade é definida pela ausência de gestação em um período de um ano de atividade sexual regular sem o uso de métodos contraceptivos (Zegers-Hochschild, Nygren et al., 2006). As principais causas de infertilidade são as disfunções ovulatórias, as doenças tuboperitoneais, as alterações seminais e as moléstias uterinas. Em até $10 \%$ dos casais a causa da infertilidade não pode ser determinada (Balasch, 2000; Crosignani e Rubin, 2000). O primeiro tratamento para infertilidade abordava a disfunção ovulatória e ocorreu no final da década de 50. O grande avanço na área ocorreu com a primeira fertilização in vitro (FIV) em 1978 (Gemzell, Diczfalusy et al., 1958; Steptoe e Edwards, 1978).

Segundo relatório da Organização Mundial da Saúde de 2004 a infertilidade atinge em todo o planeta $15 \%$ dos casais em idade reprodutiva (Zegers-Hochschild, Adamson et al., 2009). Nos últimos 30 anos têm se observado uma redução gradativa nas taxas de infertilidade na maior parte dos países (Rutstein, 2004). Isto se deve ao maior acesso aos centros de reprodução humana mesmo em países em desenvolvimento, à difusão do conhecimento acerca da infertilidade e à melhora no diagnóstico desta afecção (Rutstein, 2004). É importante destacar que essa tendência ocorreu mesmo com alterações nos hábitos sociais, com casamentos mais tardios, e na sexualidade humana, com maior multiplicidade de parceiros que tendem a reduzir a fertilidade (Rutstein, 2004; WHO | Mother or nothing: the agony of infertility, 2010). 
A OMS estima que a demanda de casais que deveriam realizar fertilização in vitro seria de 1500 ciclos para cada milhão de habitantes (Kröger e Ejzenberg, 2012). Levantamento de 2002 mostrava em nosso País apenas 180 ciclos por milhão de habitantes, com uma demanda reprimida na oferta de tratamento em torno de 10 vezes (Kröger e Ejzenberg, 2012). Ao analisamos o número de nascimentos por fertilização in vitro também encontramos uma taxa em torno de 100 vezes inferior ao de países em que o acesso aos tratamentos é irrestrito, como na Dinamarca (Pinborg, Loft et al., 2004; Schmidt, Sobotka et al., 2012)

Nos centros de reprodução humana, a busca para reduzir os casos de insucesso nos casais já tratados por FIV, tem caminhado em dois sentidos - a seleção embrionária pré-implantacional e a avaliação endometrial. Muitos destes casais inférteis originam grande percentual de embriões inviáveis, com alteração do número e estrutura dos 23 pares de cromossomos. Isto pode ser diagnosticado pela biópsia pré-implantacional, que possibilita a transferência de embriões euplóides, e resulta em até $70 \%$ de gestações (Gutierrez-Mateo, Colls et al., 2011). Os 30\% de casos inférteis pós-FIV mesmo com diagnóstico pré implantacional, constituem a fronteira atual do conhecimento na infertilidade humana. Como hipótese, pode ser considerada que parte desses casos inférteis pode resultar ainda de problemas embrionários, como lesões causadas pela biópsia, translocações balanceadas ou alterações gênicas não detectáveis pela biópsia. Em outra vertente, são possíveis alterações na interação embrião-endométrio que resultem em infertilidade ou perda gestacional recorrente. (Simpson, 2010). O estudo do endométrio pode trazer 
importantes informações fisiopatológicas que nos auxiliarão na melhora dos tratamentos de reprodução assistida.

\section{1- O endométrio}

O útero já era estudado desde 2500 A.C., conforme descrição em papiros egípcios, a partir de cadáveres mumificados, em que se verificava a separação da vagina e do útero. A primeira descrição pormenorizada do útero foi realizada por Sorano de Efesus que viveu entre 98 e 138 DC e foi Andrea Vesalius no século XVI quem descreveu a cavidade endometrial (Fritz, 2011).

Quanto aos aspectos embriológicos, foi descrito o início da formação do endométrio na vigésima semana de gestação e a completa formação da cavidade endometrial na vigésima segunda semana de gestação. $O$ endométrio

é considerado um dos tecidos mais complexos do organismo por responder a estímulos endócrinos, parácrinos e autócrinos, e pelas suas variações ao longo do ciclo menstrual. Na espessura do endométrio, os dois terços superficiais são denominados camada funcional, que se renova a cada ciclo menstrual, e o terço inferior é denominado camada basal, que dá origem à camada funcional. A camada funcional é o local de implantação embrionária (Fritz, 2011)

\section{2- O endométrio na fase de implantação}

A descrição dos diversos aspectos do endométrio durante o ciclo menstrual foi inicialmente descrita por Rock e Bartlett em 1937 e aprimorada por Noyes e colaboradores na década de 50 (Rock e Bartlett, 1937; Noyes, Hertig et al., 1975). No endométrio ocorrem alterações anatômicas e funcionais no epitélio superficial, estroma, glândulas e vasos, ao longo do ciclo. O 
endométrio desta forma é classificado como menstrual, proliferativo e secretor 50 (Rock e Bartlett, 1937; Noyes, Hertig et al., 1975). O endométrio na fase secretora ou lútea é responsivo a estrogênio e progesterona, tem limitado crescimento e apresenta aumento na tortuosidade das glândulas mucosas e dos vasos espiralados. Esses aspectos histológicos resultam da ovulação, e tem início com o aparecimento de vacúolos intracitoplasmáticos de glicogênio em posição subnuclear, em torno do $17^{\circ}$ dia do ciclo (Fritz, 2011). Outros sinais da primeira metade da fase lútea também são percebidos nas glândulas como presença de mitoses, pseudoestratificação do núcleo e aumento da secreção glandular (Fritz, 2011).

A janela de implantação ocorre 5 a 10 dias após o pico de LH ou 3 a 4 dias após a ovulação, o que corresponde ao período entre os dias 16 e 22 de um ciclo ideal de 28 dias (Lessey, 2011). Após a concepção, na tuba uterina, o embrião passa a dividir-se e é transportado para a cavidade uterina, onde chega em estágio de mórula. O número de células embrionárias rapidamente aumenta, até atingir 32 a 256 células, e constitui o blastocisto, que perde a zona pelúcida para implantar-se, entre 1 e 3 dias após a chegada na cavidade (Serafini, Silva et al., 2009; Fritz, 2011). O local de implantação do embrião é habitualmente na porção superior da parede posterior, no plano sagital médio. No momento da implantação, o endométrio pode atingir entre 10 e $14 \mathrm{~mm}$ de espessura e apresentar grande quantidade de glicogênio e lípides (Lessey, 2011). A implantação abrange uma complexa interação entre o endométrio e o embrião, que frequentemente não logra um resultado favorável - em um ciclo natural de pacientes saudáveis a taxa máxima de implantação é de apenas 40\% (Simpson, 2010). A pesquisa dos marcadores genéticos e protéicos 
relacionados à implantação teve início há cerca de 40 anos e as amostras de tecido endometrial para estudo são obtidas por biópsia aspirativa (Serafini, Silva et al., 2009; Zanatta, Rocha et al., 2010; Lessey, 2011).

\section{3- Técnicas de biópsia endometrial}

A biópsia do endométrio foi durante longo período realizada às cegas, e mais recentemente pode ser obtida de forma dirigida (Bettocchi, 1996). A avaliação histológica do tecido pode ser considerada suficiente quando a amostra tem ao menos $0,5 \mathrm{~mm}^{2}$. A biópsia realizada às cegas pode ser realizada em ambulatório, com emprego de dispositivos como a cureta de Novak, sonda uretral, cateteres de Vabra e Pipelle, ou em ambiente cirúrgico através da dilatação cervical e curetagem uterina. Entre os dispositivos para biópsia endometrial ambulatorial, a sonda de Pipelle tem mostrado superioridade frente aos demais (Farrell, Jones et al., 1999; Ceci, Bettocchi et al., 2002; Polena, Mergui et al., 2007; Williams, Brechin et al., 2008).

Na biópsia dirigida, utiliza-se a técnica e o equipamento desenvolvidos por Stefano Bettocchi em 1996, com histeroscópio de formato oval de $5 \mathrm{~mm}$ com canal operatório de 5F (Bettocchi, 1996). As biópsias dirigidas podem ser realizadas por punção ("punch") ou com pequeno arrasto da pinça sobre a área biopsiada ("grasp"). Estudo de Bettocchi e colaboradores de 2002 mostraram que a técnica de arraste é superior à punção nas biópsias dirigidas, fornecendo amostra de tamanho três vezes superior $\left(5,7 \mathrm{~mm}^{2}\right.$ ) (Bettocchi, Di Venere et al., 2002). A retirada do material pelo canal operatório afasta a possibilidade de contaminação da amostra por tecido proveniente de fora da área de biópsia. 


\section{4- Indicações da biopsia endometrial}

A avaliação do endométrio é amplamente empregada nos casos de sangramento uterino anormal para a detecção de processos neoplásicos e hiperplasias. Porém, a avaliação às cegas parece pouco sensível para diagnóstico de parte das doenças uterinas. Em 2001 Bettocchi e colaboradores encontraram $62,5 \%$ de falha diagnóstica na curetagem uterina, frente aos achados verificados nas peças cirúrgicas de histerectomia (Bettocchi, Ceci et al., 2001). Este índice de falha pode ser ainda maior em casos de alteração focal do endométrio (Farrell, Jones et al., 1999).

Em contrapartida, através da biópsia dirigida Loverro em 1996 encontrou à histeroscopia sensibilidade de 95\% e especificidade de $98 \%$ para casos de hiperplasia; e em 1999 verificou sensibilidade de 95\% e especificidade de $100 \%$ no diagnóstico, a partir dos achados histológicos obtidos em pacientes na menopausa que apresentavam menorragia (Loverro, Bettocchi et al., 1996). Resultados semelhantes foram verificados com a biópsia dirigida em 2002 por Ceci e colaboradores que verificaram em 443 pacientes uma sensibilidade diagnóstica de $98 \%$ e especificidade de $95 \%$. Esses autores avaliaram os achados histeroscópicos frente à histerectomia, para casos de sangramento uterino anormal, espessamento endometrial na pós-menopausa, pólipos endometriais e miomas submucosos (Ceci, Bettocchi et al., 2002).

No estudo da infertilidade a biópsia endometrial é realizada desde 1949, na fase lútea tardia, para verificar a ovulação em determinado ciclo e, eventualmente, para demonstrar casos de insuficiência lútea. Esse diagnóstico era estabelecido quando ocorria atraso na datação endometrial em dois ciclos 
seguidos (Revel, 2012). Persistem na literatura médica as controvérsias acerca da real prevalência da insuficiência lútea, do diagnóstico preciso desta deficiência entre a população infértil, e da necessidade de realizar a biópsia endometrial na investigação básica destes casais (Crosignani e Rubin, 2000; Fatemi, 2009).

São escassos até 0 momento deste estudo a avaliação histomorfométrica do endométrio de mulheres inférteis através de biópsia às cegas, e não foi feita a comparação nestas pacientes da biópsia dirigida versus biópsia aspirativa às cegas.

\section{5- Morfometria}

O primeiro relato de morfometria do endométrio pertence a um autor holandês publicado em 1974. Apenas em 1991 surgiu um estudo que envolveu a análise morfométrica para pacientes inférteis, comparando o endométrio de pacientes que utilizaram dois protocolos diferentes de estimulação ovariana (Rogers, Polson et al., 1991; Rogers e Murphy, 1992). Nestes estudos, alterações morfométricas como redução no número de glândulas e do volume glandular não foram reconhecidas na avaliação morfológica (Rogers, Polson et al., 1991; Rogers e Murphy, 1992). Estudo de Artacho-Perula de 1992 com histomorfometria de amostras de endométrio de mulheres saudáveis e com suspeita de neoplasia endometrial encontraram, entre as saudáveis, um aumento de $144 \%$ das glândulas da fase proliferativa para a fase lútea, acompanhado de aumento da espessura endometrial. Houve concordância dos patologistas na classificação da fase lútea em $97 \%$ dos casos (Artacho-Perula 1992 e 1993). Estudo inglês de 2004 envolveu 20 pacientes com infertilidade 
sem causa aparente, 22 com infertilidade tuboperitonial e 21 pacientes férteis; e não encontrou diferença na análise anatomopatológica de fragmento endometrial, obtido por cureta de Sharman da parede anterior. Porém, verificaram uma tendência para atraso na maturação endometrial nas pacientes com fator tuboperitoneal frente às demais (Edi-Osagie, Seif et al., 2004).

A literatura que avalia a morfometria em pacientes com infertilidade é escassa. Através da pesquisa no PubMed com os descritores endométrio e morfometria em humanos e em inglês encontramos apenas 37 estudos, sendo que apenas 5 envolviam pacientes inférteis. Nenhum destes trabalhos, já citados, foi realizado com biópsia dirigida, e as amostras de pacientes também incluíam casos de abortamento de repetição. 


\section{2- Objetivos}

2.1- Objetivo principal

1- Avaliar a histomorfometria do endométrio na fase lútea de mulheres férteis e inférteis.

2.2- Objetivo secundário

1- Comparar a histomorfometria das diferentes porções do útero em pacientes férteis e inférteis.

2- Comparar a histomorfometria em pacientes férteis versus pacientes com três fatores de infertilidade - tuboperitonial, endometriose e masculino. 


\section{3- Métodos}

\section{1- Casuística}

A partir de agosto de 2009, foram selecionados 30 casos para compor o grupo de estudo, entre as pacientes inférteis em acompanhamento no Centro de Reprodução Humana Mário Covas do Hospital das Clinicas da Faculdade de Medicina da USP. Os critérios seletivos adotados foram: idade entre 21 até 42 anos, infertilidade primária, ciclos menstruais regulares com intervalo de até 40 dias, ausência de moléstias de base ou medicações de uso contínuo. Foram considerados critérios de exclusão: cirurgia endometrial prévia, utilização de método contraceptivo hormonal nos 3 meses precedentes à inclusão no estudo, falta durante o seguimento ultrassonográfico, alteração da cavidade endometrial à histeroscopia (pólipo endometrial, mioma submucoso, sinéquia). Para efeito de análise secundária as pacientes do grupo infértil foram subdivididas segundo a causa de infertilidade em endometriose, alteração tubária (como sequela de moléstia inflamatória pélvica, diagnosticada por videolaparoscopia) e infertilidade de causa masculina.

Na mesma data de seleção dos casos foi constituído um grupo controle, com 10 pacientes comprovadamente férteis, matriculadas entre as pacientes do setor de planejamento familiar da Clínica Ginecológica do Hospital das Clinicas da FMUSP. Os critérios seletivos do grupo controle foram: parto prévio, idade entre 21 e 42 anos, ciclo menstrual regular com intervalo até 40 dias, ausência de doença de base ou ginecológica, a partir de dados da anamnese, exame físico e dados de prontuário. Foram considerados critérios de exclusão: 
cirurgia endometrial prévia, utilização de método contraceptivo hormonal nos 3 meses precedentes à inclusão no estudo. Adicionalmente, foram também excluídos os casos e os controles que faltaram durante seguimento ultrassonográfico, e os que apresentaram alterações da cavidade endometrial à histeroscopia - pólipo endometrial, mioma submucoso, e sinéquia.

Todas as pacientes selecionadas tiveram os dados clínicos e o exame físico conferidos pelo autor para confirmação da anamnese, antecedentes cirúrgicos, uso de medicamentos de forma contínua, moléstias de base, antecedentes obstétricos e menstruais.

\section{2- Procedimentos}

Todas as pacientes foram submetidas à ultrassonografia pélvica seriada a partir de um episódio menstrual para monitorização da foliculogênese e determinação do período ovulatório (Shoupe, Mishell et al., 1989). Todos os exames ultrassonográficos foram realizados pelo autor, com intervalo máximo de 3 dias a partir do sexto dia do ciclo. Após a verificação da ovulação era realizada histeroscopia diagnóstica dentro do período estipulado, do $16^{\circ}$ ao $22^{\circ}$ dia do ciclo menstrual (fase lútea media).

As histeroscopias diagnósticas foram realizadas no ambulatório de Ginecologia do Hospital das Clinicas da FMUSP pelo autor. Não foi utilizado pinça de Pozzi para tração do colo uterino em nenhum caso. Foi utilizado soro fisiológico como meio de distensão com suporte colocado um metro acima da paciente que proporciona uma pressão intrauterina de $120 \mathrm{mmHg}$ e camisa de Bettocchi com diâmetro final de $5 \mathrm{~mm}$. Após inspeção da cavidade uterina era realizada com pinça de preensão a biópsia dirigida da parede posterior do 
fundo uterino, seguida de biópsia da parede anterior em seu terço médio (esquema e foto abaixo), ambas através da técnica de arraste (Bettocchi, Di Venere et al., 2002). As amostras eram imediatamente colocadas em frascos apropriadamente identificados. Logo a seguir era realizada uma terceira biópsia endometrial, aspirativa e às cegas, com Pipelle de Cornier, com sua abertura voltada para a parede posterior. Este material também era imediatamente colocado em formol em frasco identificado do paciente.

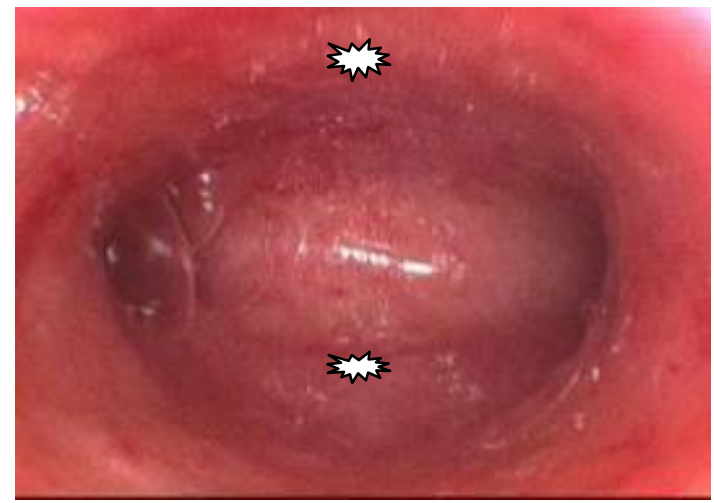

Fonte: Unifesp (site)

Figura 1- Foto e esquema da cavidade uterina e pontos de biópsia.

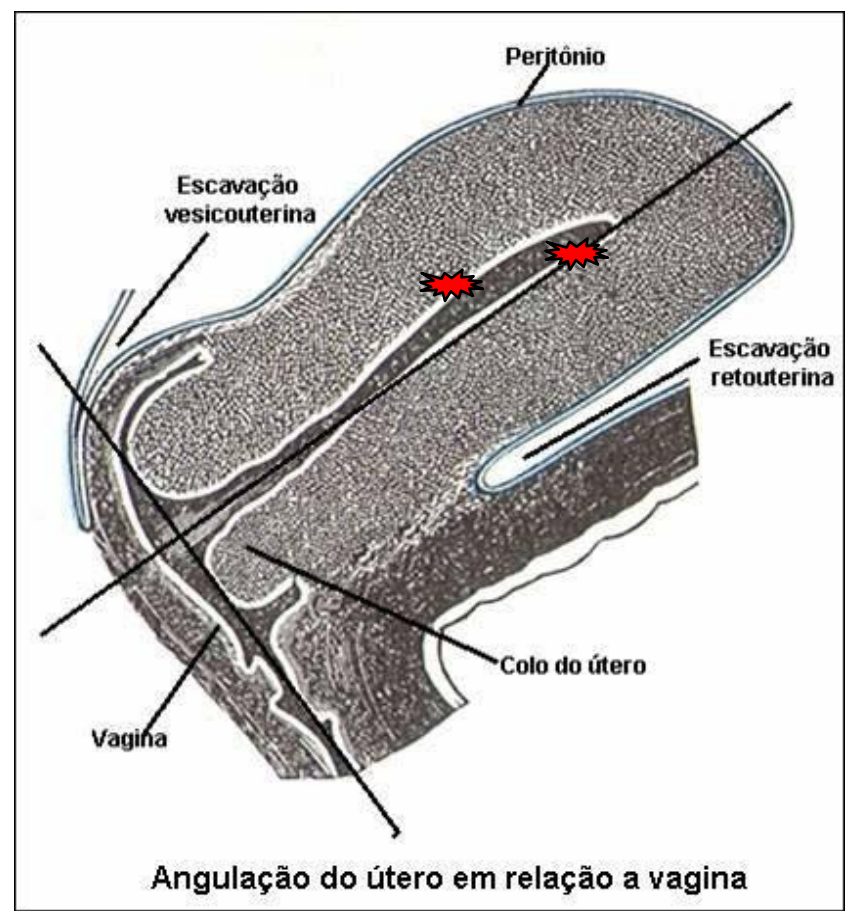




\section{3- Processamento do material}

\subsection{1- Fixação e Inclusão}

Após o período de fixação, as peças foram desidratadas em concentrações crescentes de álcool etílico, diafanizados pelo xilol e impregnados pela parafina líquida em estufa regulada à temperatura de $60^{\circ}$. (Kulay Júnior, Simões et al., 1980)

\subsection{2- Microtomia}

Após a inclusão, foram obtidos cortes seriados de $4 \mu \mathrm{m}$ utilizando-se um micrótomo manual LEICA - RM 2145. Os cortes foram montados em lâminas histológicas contendo uma fina camada de albumina e numerados conforme a sua ordem de corte.

\subsection{3- Métodos de coloração}

Os cortes histológicos foram desparafinados em xilol e hidratados, e corados pela hematoxilina e eosina (HE).

\section{4- Análise Morfométrica}

As lâminas foram analisadas sob microscopia de luz Axiolab Standart 2.0, acoplado a uma videocâmara de alta resolução (AxionCam Carl Zeiss, Jena, Alemanha $)^{\circledR}$ que transmite a imagem a um computador. Nas biópsias dirigidas (parede anterior e posterior) foram medidas a espessura do epitélio superficial 
(aumento de 40X -10 medidas), a altura da célula glandular (aumento de 40X15 medidas em 3 glândulas diferentes), o número de glândulas em área predeterminada (aumento de 10X) e a área circular da glândula (aumento de 40X- em 3 glândulas diferentes). Nas biópsias aspirativas estas medidas foram realizadas em três áreas diferentes de cada amostra escolhidas de forma aleatória.

\section{5- Análise Histopatológica}

A leitura das lâminas para datação e detecção de alterações histopatológicas foi realizada por um histologista e dois patologistas independentes todos com experiência superior a dez anos na área e que realizaram a leitura de forma cega acerca da técnica de coleta (dirigida ou às cegas), origem (parede anterior, posterior), e grupo da paciente - fértil ou infértil. No exame histopatológico foram caracterizados o dia do ciclo segundo os critérios de Noyes, a classificação segundo a fase do ciclo em proliferativa ou lútea, a quantidade de fragmentos, a homogeneidade do material, a suficiência da amostra para análise e a presença de endometrite e/ou hemorragia tecidual (Noyes, Hertig et al., 1975; Kasius, Broekmans et al., 2012).

\section{6- Ética}

Esta pesquisa foi aprovada pelo comitê de Ética do Hospital das Clinicas da FMUSP sob o protocolo numero 144/09.

\section{7- Método Estatístico}


Foram comparados os grupos infértil e fértil, e os subgrupos do grupo infértil entre si. Inicialmente as variáveis foram testadas quanto à sua distribuição para a opção por testes paramétricos ou não-paramétricos através do teste de Shapiro-Wilk. A análise das variáveis quantitativas envolveu o cálculo da média, desvio-padrão, valor mínimo, máximo e mediana. Para avaliação das variáveis qualitativas foram comparadas as frequências absolutas e relativas. A comparação entre as diversas áreas do endométrio foi feita através da análise de variância. Para verificação da validade da amostra selecionada foi realizado o cálculo do poder dos testes empregados.

\section{4- Resultados}

\section{1- Dados clínicos}

Das 40 mulheres inicialmente selecionadas apenas 26 completaram 0 protocolo, 20 pacientes do grupo infértil e 6 pacientes do grupo controle. Quatorze pacientes foram excluídas da pesquisa por falta durante o período de acompanhamento ultrassonográfico (12 pacientes), e alteração da cavidade uterina na histeroscopia (pólipo-2 pacientes). As causas de infertilidade eram: fator tuboperitoneal, como sequela de doença inflamatória pélvica (DIP) em 8 pacientes, endometriose em 5 pacientes, fator masculino em 5 pacientes, e infertilidade sem causa aparente em 2 pacientes.

Foram realizadas 78 biópsias nas 26 pacientes, e destas foram consideradas adequadas para avaliação 77 amostras, 18 do grupo controle e 59 do grupo infertilidade. 
Em relação à idade das pacientes, a média do grupo controle foi de 32,2 anos e no grupo infertilidade foi de 35,3 anos, mas esta diferença não foi significativa (Tabela 1). Também, não houve diferença referente à idade das pacientes do grupo controle e dos subgrupos inférteis Tabela 2.

Tabela 1: Idade das pacientes dos grupos controle e infértil

\begin{tabular}{|c|c|c|c|c|c|c|}
\hline \multicolumn{7}{|c|}{ Grupo controle } \\
\hline $\begin{array}{l}\text { Idade } \\
\text { (anos) }\end{array}$ & $\begin{array}{l}N \\
6\end{array}$ & $\begin{array}{c}\text { Média } \\
32,2\end{array}$ & $\begin{array}{l}\text { DP } \\
7,1\end{array}$ & $\begin{array}{c}\text { Mediana } \\
32,0\end{array}$ & $\begin{array}{c}\text { Mínimo } \\
22,0\end{array}$ & $\begin{array}{c}\text { Máximo } \\
42,0\end{array}$ \\
\hline $\begin{array}{l}\text { Idade } \\
\text { (anos) }\end{array}$ & $\begin{array}{l}N \\
20\end{array}$ & $\begin{array}{c}\text { Média } \\
35,3\end{array}$ & $\begin{array}{r}\text { Gupo } \\
\text { DP } \\
4,8\end{array}$ & $\begin{array}{c}\text { Mediana } \\
35,0\end{array}$ & $\begin{array}{c}\text { Mínimo } \\
28,0\end{array}$ & $\begin{array}{l}\text { Máximo } \\
42,0\end{array}$ \\
\hline
\end{tabular}

teste t de Student, $p=0,277$

Tabela 2: Idade das pacientes do grupo controle e subgrupos inférteis

\begin{tabular}{|c|c|c|c|c|c|c|}
\hline \multicolumn{7}{|c|}{ Grupo controle } \\
\hline $\begin{array}{l}\text { Idade } \\
\text { (anos) }\end{array}$ & $\begin{array}{l}N \\
6\end{array}$ & $\begin{array}{c}\text { Média } \\
32,2\end{array}$ & $\begin{array}{l}\text { DP } \\
7,1\end{array}$ & $\begin{array}{c}\text { Mediana } \\
32,0\end{array}$ & $\begin{array}{l}\text { Mínimo } \\
22,0\end{array}$ & $\begin{array}{l}\text { Máximo } \\
42,0\end{array}$ \\
\hline $\begin{array}{l}\text { Idade } \\
\text { (anos) }\end{array}$ & $\begin{array}{l}N \\
8\end{array}$ & $\begin{array}{c}\text { Média } \\
35,3\end{array}$ & $\begin{array}{l}\text { upo } t \\
\text { DP } \\
4,9\end{array}$ & $\begin{array}{c}\text { Mperitone } \\
\text { Mediana } \\
36,5\end{array}$ & $\begin{array}{l}\text { Mínimo } \\
28,0\end{array}$ & $\begin{array}{l}\text { Máximo } \\
41,0\end{array}$ \\
\hline \multicolumn{7}{|c|}{ Grupo endometriose } \\
\hline $\begin{array}{l}\text { Idade } \\
\text { (anos) }\end{array}$ & $\begin{array}{l}N \\
5\end{array}$ & $\begin{array}{c}\text { Média } \\
36,7\end{array}$ & $\begin{array}{l}\mathrm{DP} \\
6,1\end{array}$ & $\begin{array}{c}\text { Mediana } \\
37,5\end{array}$ & $\begin{array}{l}\text { Mínimo } \\
29,0\end{array}$ & $\begin{array}{c}\text { Máximo } \\
42,0\end{array}$ \\
\hline \multicolumn{7}{|c|}{ Grupo fator masculino } \\
\hline (anos) & 5 & 34,2 & 4,9 & 33,0 & 30,0 & 41,0 \\
\hline
\end{tabular}

ANOVA: $p=0,69$

\section{2- Data do exame}

A data de realização da histeroscopia para coleta das amostras endometriais foi determinada individualmente, pelo desenvolvimento folicular à 
ultrassonografia pélvica. O intervalo entre o início da menstruação e a data da realização da histeroscopia foi anotado em cada caso. As médias desse intervalo (em dias) para o grupo infertilidade e controle estão contidas na Tabela 3. Não houve diferença significativa entre os grupos, tendo ocorrido a coleta de amostras em média 19,9 dias após o início da menstruação no grupo infértil e 21,5 dias no grupo controle. Para os subgrupos com infertilidade, também não houve diferença significativa. As médias desse intervalo (em dias) para os subgrupos com infertilidade e controle estão contidas na Tabela 4.

Tabela 3: Intervalo (em dias) entre o início do ciclo menstrual e a realização da histeroscopia no grupo controle e no grupo infértil

\begin{tabular}{|c|c|c|c|c|c|c|}
\hline \multicolumn{7}{|c|}{ Grupo controle } \\
\hline $\begin{array}{l}\text { Intervalo } \\
\text { (dias) }\end{array}$ & $\begin{array}{r}N \\
6\end{array}$ & $\begin{array}{c}\text { Média } \\
21,5\end{array}$ & $\begin{array}{l}\text { DP } \\
3,6\end{array}$ & $\begin{array}{c}\text { Mediana } \\
21,5\end{array}$ & $\begin{array}{l}\text { Mínimo } \\
17,0\end{array}$ & $\begin{array}{l}\text { Máximo } \\
26,0\end{array}$ \\
\hline $\begin{array}{l}\text { Intervalo } \\
\text { (dias) }\end{array}$ & $\begin{array}{l}N \\
20\end{array}$ & $\begin{array}{c}\text { Média } \\
19,9\end{array}$ & DP & $\begin{array}{c}\text { Mediana } \\
19,5\end{array}$ & $\begin{array}{c}\text { Mínimo } \\
17,0\end{array}$ & $\begin{array}{l}\text { Máximo } \\
29,0\end{array}$ \\
\hline
\end{tabular}

teste não-paramétrico de Mann-Whitney: $p=0,26$

Tabela 4: Intervalo (em dias) entre o início do ciclo menstrual e a realização da histeroscopia no grupo controle e subgrupos inférteis

\begin{tabular}{|c|c|c|c|c|c|c|}
\hline \multicolumn{7}{|c|}{ Grupo controle } \\
\hline Intervalo & $\mathrm{N}$ & Média & DP & Mediana & Mínimo & Máximo \\
\hline (dias) & 6 & 21,5 & 3,6 & 21,5 & 17,0 & 26,0 \\
\hline Intervalo & $\mathrm{N}$ & Média & DP & Mediana & Mínimo & Máximo \\
\hline (dias) & 8 & 19,7 & 0,9 & 19,5 & 19,0 & 21,0 \\
\hline Intervalo & $\mathrm{N}$ & Média & DP & Mediana & Mínimo & Máximo \\
\hline (dias) & 5 & 18,3 & 1,5 & 18,0 & 17,0 & 20,0 \\
\hline & & & 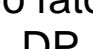 & Mediana & & \\
\hline $\begin{array}{l}\text { Intervalo } \\
\text { (dias) }\end{array}$ & 5 & $\begin{array}{l}\text { Media } \\
21 ?\end{array}$ & $\begin{array}{ll}\text { DP } \\
33\end{array}$ & $\begin{array}{l}\text { Mediana } \\
195\end{array}$ & IVIInimo & Vlaximo \\
\hline (dias) & & 21,2 & 3,3 & 19,5 & 17,0 & 26,0 \\
\hline
\end{tabular}

teste não-parmétrico de Kruskal-Wallis: $p=0,51$ 


\section{3- Análise morfométrica}

A análise morfométrica foi realizada nas amostras endometriais dos grupos fértil e infértil. Foram avaliadas a espessura do epitélio superficial, a altura da célula glandular, a área circular da glândula e o número de glândulas (ArtachoPerula, Roldan-Villalobos et al., 1992; Artacho-Perula, Roldan-Villalobos et al., 1993). As amostras foram obtidas em áreas predeterminadas da parede uterina anterior e posterior, e às cegas quanto ao local, na biópsia aspirativa. Nas biópsias aspirativas, em que a extensão do endométrio obtido é grande, foram avaliadas três áreas diferentes em cada amostra.

Os resultados da espessura do epitélio superficial de todas as pacientes, obtidos da parede anterior e posterior do útero assim como da biópsia aspirativa, estão contidos na Tabela. 5. Constata-se que a variação de espessura endometrial é grande nos três tipos de amostras estudadas. Os resultados obtidos por biópsia aspirativa, em média, foram maiores que os obtidos nas biópsias dirigidas. Não houve variação na espessura endometrial quando comparada a parede uterina posterior com a anterior. Não houve diferença significativa ao compararmos a espessura do epitélio superficial entre férteis e inférteis como consta na Tabela 6.

Tabela 5: Espessura do epitélio superficial $(\mu \mathrm{m})$ das paredes uterinas anterior (PA) e posterior (PP) e na biópsia aspirativa (ASP)

\begin{tabular}{llllll} 
Espessura & N & Média & DP & Mínimo & Máximo \\
\hline & & & & & \\
Parede anterior & 25 & 20,7 & 4,5 & 12,2 & 32,4 \\
Parede posterior & 26 & 22,1 & 5,2 & 14,1 & 31,5 \\
Aspirativa & 26 & 24,5 & 3,7 & 16,9 & 34,4
\end{tabular}

Análise de variância PA x PP x ASP $p=0,003$; PA x ASP $p<0,001$;

PP X ASP $p=0,09 ; P A \times$ PP $p=0,28$ 
Tabela 6: Espessura do epitélio superficial $(\mu \mathrm{m})$ das paredes uterinas anterior, posterior, e na biópsia aspirativa, no grupo infértil e controle

\begin{tabular}{lcccccc}
\hline Espessura & & N & Média & DP & Mínimo & Máximo \\
\hline \multirow{2}{*}{ Grupo controle } & PA & 5 & 20,9 & 2,4 & 18,1 & 23,9 \\
& PP & 6 & 18,5 & 4,4 & 12,2 & 22,3 \\
& ASP & 6 & 22,6 & 3,5 & 17,8 & 27,1 \\
Grupo infértil & & & & & & \\
& PA & 20 & 20,6 & 4,9 & 12,2 & 32,4 \\
& PP & 20 & 22,2 & 5,4 & 14,1 & 31,5 \\
& ASP & 20 & 24,3 & 4,0 & 16,9 & 34,4 \\
\hline
\end{tabular}

Parede anterior (PA) ; posterior (PP) ; biópsia aspirativa (ASP) ASP $\mathrm{p}=0,36$; $\mathrm{PA} \mathrm{p}=0,89 ; \mathrm{PP} \mathrm{p}=0,16$

Os resultados da espessura do epitélio superficial das pacientes do grupo controle e dos subgrupos inférteis, obtidos da parede anterior e posterior do útero, e por aspiração, estão contidos na Tabela 7. Constata-se que a variação de espessura endometrial é grande tanto na parede anterior como na parede posterior do útero, nos subgrupos inférteis. Não houve variação na espessura endometrial quando comparada a parede uterina posterior em comparação com a anterior. Os resultados obtidos por biópsia aspirativa, sem determinação do local avaliado, foram semelhantes aos da biópsia dirigida. 
Tabela 7: Espessura do epitélio superficial $(\mu \mathrm{m})$, da parede uterina anterior, posterior, e na biópsia aspirativa, subgrupos inférteis e controle

\begin{tabular}{|c|c|c|c|c|c|}
\hline \multicolumn{6}{|c|}{ Grupo controle } \\
\hline & $\mathrm{N}$ & Média & DP & Mínimo & Máximo \\
\hline PA & 5 & 20,9 & 2,4 & 18,1 & 23,9 \\
\hline PP & 6 & 18,4 & 4,3 & 12,2 & 22,3 \\
\hline \multirow[t]{2}{*}{ ASP } & 6 & 22,6 & 4,8 & 16,2 & 36,3 \\
\hline & $\mathrm{N}$ & \multicolumn{3}{|c|}{ Média Grupo tuboperitoneal --- } & Máximo \\
\hline PA & 8 & 22,5 & 5,4 & 17,6 & 32,4 \\
\hline PP & 8 & 23,7 & 5,4 & 17,0 & 30,6 \\
\hline \multirow[t]{2}{*}{ ASP } & 8 & 24,9 & 6,0 & 15,7 & 33,1 \\
\hline & $\mathrm{N}$ & \multicolumn{3}{|c|}{---- Grupo endometriose ---- } & Máximo \\
\hline PA & 5 & 16.9 & 2,5 & 14,2 & 19.9 \\
\hline PP & 5 & 19,5 & 5,4 & 14,0 & 27,6 \\
\hline \multirow[t]{2}{*}{ ASP } & 5 & 21,6 & 3,5 & 16,7 & 28,7 \\
\hline & $\mathrm{N}$ & \multicolumn{3}{|c|}{ Grupo fator masculino --- } & Máximo \\
\hline PA & 5 & 18.9 & 3.9 & 12.2 & 22.2 \\
\hline $\mathrm{PP}$ & 5 & 22,2 & 6,0 & 16,4 & 31,5 \\
\hline ASP & 5 & 25,6 & 5,6 & 16,7 & 37,4 \\
\hline
\end{tabular}

A área circular das glândulas endometriais obtidas por biópsia dirigida e aspirativa, foi determinada, e está contida na Tabela 8. A comparação mostrou que a área obtida por biópsia aspirativa (ASP) é significativamente maior que a obtida nas biópsias dirigidas (PA e PP) que não diferem entre si.

Tabela 8: Área circular das glândulas endometriais obtida por biópsia dirigida em dois sítios uterinos e por aspiração (médias $\mu \mathrm{m}^{2}$ )

\begin{tabular}{cccccc}
\hline Área da amostra & N & Média & DP & Mínimo & Máximo \\
& & & & & \\
\hline PA & 25 & 7787,6 & 2795,3 & 3899,0 & 15828,1 \\
PP & 26 & 8649,2 & 3071,5 & 3627,3 & 14914,2 \\
ASP & 26 & 11526,1 & 2857,9 & 6414,7 & 18006,4
\end{tabular}

Parede anterior (PA) ; posterior (PP) ; biópsia aspirativa (ASP)

Analise de variância ASP x PA x PP $p<0,001$; PA x PP $p=0,09$ 
A área circular das glândulas endometriais obtida por biópsia dirigida e às cegas também foi determinada nos grupos- infértil e controle e estão contidos na Tabela 9. A comparação mostrou que a área glandular não difere nos dois grupos, quando feita a avaliação no mesmo local e método.

Tabela 9: Área circular das glândulas endometriais nas paredes uterinas, nos grupos controle e infértil (médias $\mu \mathrm{m}^{2}$ )

\begin{tabular}{lccrrrr} 
Área glandular & Local & $\mathrm{N}$ & \multicolumn{1}{c}{ Média } & DP & Mínimo & Máximo \\
\hline Controle & ASP & 6 & 12524,5 & 1885,3 & 10325,4 & 16026,4 \\
& PA & 5 & 8973,8 & 3136,0 & 5426,9 & 13079,3 \\
& PP & 6 & 8033,0 & 3894,0 & 4407,5 & 14914,2 \\
Infértil & & & & & & \\
& ASP & 20 & 11142,3 & 2954,6 & 6414,7 & 18006,4 \\
& PA & 20 & 7298,9 & 2746,6 & 3899,0 & 15828,1 \\
& PP & 20 & 8620,6 & 2952,1 & 3627,3 & 14216,7 \\
\hline
\end{tabular}

Parede anterior (PA) ; posterior (PP) ; biópsia aspirativa (ASP) teste $t$ controle $x$ infértil $P A p=0,24 ; P P \quad p=0,69 ; A S P p=0,29$

Os resultados da altura da célula na glândula endometrial de todas as pacientes, obtidos da parede anterior e posterior do útero assim como da biópsia aspirativa, estão contidos na Tabela 10. Constata-se que a variação de altura é grande nos três tipos de amostras estudadas. Os resultados obtidos por biópsia aspirativa foram maiores dos que nas biópsias dirigidas, por análise de variância. Não houve variação na altura celular quando comparadas as glândulas da parede uterina posterior com a anterior. Não houve diferença significativa ao compararmos a altura celular nas glândulas endometriais entre férteis e inférteis, como observado na Tabela 11. 
Tabela 10: Altura celular na glândula endometrial $(\mu \mathrm{m})$ de todos os casos, obtida por biópsia dirigida em dois sítios uterinos e por aspiração

\begin{tabular}{cccccc}
\hline Área da amostra & N & Média & DP & Mínimo & Máximo \\
\hline PA & 25 & 20,9 & 3,6 & 14,7 & 28,7 \\
PP & 26 & 21,4 & 3,8 & 14,6 & 30,4 \\
ASP & 26 & 24,5 & 2,7 & 18,2 & 28,8
\end{tabular}

Parede anterior (PA) ; posterior (PP) ; biópsia aspirativa (ASP)

PA $\times$ PP $\times$ ASP $p=0,001$; ASP $\times$ PA $p<0,001$; ASP X PP $p=0,001$;

PA $x$ PP $p=0,47$

Tabela 11: Altura celular na glândula endometrial $(\mu \mathrm{m})$, obtida por biópsia dirigida em dois sítios uterinos e por biópsia aspirativa (médias $\mu \mathrm{m}^{2}$ )

\begin{tabular}{|c|c|c|c|c|c|c|}
\hline Altura celular & Local & $\mathrm{N}$ & Média & DP & Mínimo & Máximo \\
\hline \multirow[t]{3}{*}{ Controle (F) } & $\overline{\mathrm{ASP}}$ & 6 & 25,2 & $\overline{3,0}$ & 21,2 & 28,8 \\
\hline & PA & 5 & 21,3 & 5,5 & 14,4 & 28,7 \\
\hline & PP & 6 & 20,5 & 3,9 & 14,4 & 24,7 \\
\hline \multirow[t]{3}{*}{ Infértil } & ASP & 20 & 24,2 & 2,7 & 18,2 & 28,7 \\
\hline & PA & 20 & 20,8 & 3,2 & 14,8 & 26,4 \\
\hline & PP & 20 & 21,3 & 4,1 & 14,6 & 30,4 \\
\hline
\end{tabular}

Paredes anterior (PA) ; posterior (PP) ; biópsia aspirativa (ASP) ASP F $x$ INF $p=0,42$; PA F $x$ PA INF $p=0,77$; PP F $\times$ PP INF $p=0,66$

O número de glândulas em área pré-determinada obtida da parede anterior e posterior do útero, assim como da biópsia aspirativa, entre férteis e inférteis, estão contidos na Tabela 12. Não houve diferença significativa no número de glândulas nestes grupos. 
Tabela 12: Número de glândulas por biópsia dirigida em dois sítios uterinos e por biópsia aspirativa

\begin{tabular}{|c|c|c|c|c|c|c|}
\hline Altura celular & Local & $\mathrm{N}$ & Média & DP & Mínimo & Máximo \\
\hline \multirow{3}{*}{ Controle (F) } & ASP & 6 & 17,1 & 2,4 & 14,0 & 20,0 \\
\hline & PA & 5 & 17,2 & 6,0 & 11,0 & 26,0 \\
\hline & PP & 6 & 18,0 & 6,7 & 13,0 & 29,0 \\
\hline \multirow[t]{3}{*}{ Infértil (INF) } & ASP & 20 & 17,0 & 4,1 & 6,0 & 24,0 \\
\hline & PA & 20 & 14,7 & 5,8 & 5,0 & 27,0 \\
\hline & PP & 20 & 15,8 & 5,1 & 8,0 & 24,0 \\
\hline
\end{tabular}

Paredes anterior (PA) ; posterior (PP); biópsia aspirativa (ASP)

ASP F $x$ INF $p=1,0$; PA F $x$ INF $p=0,56$; PP F $x$ INF $p=0,72$

\section{4- Análise Histológica}

\subsection{1- Representatividade da amostra}

Foram realizadas 78 biópsias, conforme programado, 52 dirigidas e 26 aspirativas. Apenas uma amostra dirigida da parede anterior não pôde ser analisada por artefato técnico. Entre as biópsias dirigidas, 46 amostras (88,4\%) tinham quantidade de material moderada para análise e 6 amostras (11,6\%) tinham pouco material, porém suficiente para análise. Entre as biópsias aspirativas, $3(11,5 \%)$ foram consideras com moderada quantidade de material e $23(88,5 \%)$ com quantidade abundante.

\subsection{2- Datação}

Dois patologistas realizaram a datação endometrial às cegas quanto à origem das amostras e não houve entre eles divergência quanto à fase do ciclo menstrual. Houve diferença de um dia na datação em cinco casos. Os dados relativos à datação das biópsias da parede anterior (PA), parede posterior (PP), e aspirativa (ASP) estão contidos na Tabela 13. Não houve diferença na datação endometrial segundo o local e método de coleta. 
Tabela 13: Resultados da datação (em dias) do endométrio na parede anterior e posterior , e por biópsia aspirativa

\begin{tabular}{lccccccc}
\hline LOCAL & N & Média & DP & Mínimo & Máximo & Mediana & p \\
\hline PP & 26 & 17,6 & 2,4 & 11,0 & 21,0 & 18,0 & \\
PA & 25 & 17,6 & 2,8 & 11,0 & 21,0 & 19,0 & 0,31 \\
ASP & 26 & 18,7 & 2,6 & 12,0 & 23,0 & 19,0 & \\
\hline \multicolumn{7}{l}{ parede anterior (PA), parede posterior (PP), e aspirativa (ASP) }
\end{tabular}

Os dados relativos à datação das biópsias endometriais (em dias do ciclo), segundo o local avaliado e a fertilidade, estão contidos na Tabela 14. Não houve diferença na datação endometrial segundo o local avaliado e a fertilidade.

Tabela 14: Resultados da datação (em dias) do endométrio segundo local de coleta e a fertilidade

\begin{tabular}{lcccccccc}
\hline Grupo & Local & $\mathbf{N}$ & Média & $\mathbf{d p}$ & Mínimo & Máximo & Mediana & $\mathbf{p}$ \\
\hline Infértil & PP & 20 & 17,4 & 2,6 & 11,0 & 21,0 & 18,0 & $\mathbf{0 , 9 7}$ \\
Controle & PP & 6 & 18,3 & 1,0 & 17,0 & 20,0 & 18,0 & \\
& & & & & & & & \\
Infértil & PA & 20 & 17,4 & 3,1 & 11,0 & 21,0 & 18,5 & $\mathbf{0 , 4 8}$ \\
Controle & PA & 5 & 18,8 & 1,3 & 17,0 & 20,0 & 19,0 & \\
& & & & & & & & \\
Infértil & ASP & 20 & 18,6 & 2,8 & 12,0 & 23,0 & 18,5 & $\mathbf{0 , 9 0}$ \\
Controle & ASP & 6 & 19,6 & 2,3 & 17,0 & 23,0 & 19,0 & \\
\hline \multicolumn{7}{l}{ parede anterior (PA), parede posterior (PP), e aspirativa (ASP) }
\end{tabular}

Os dados relativos à datação das biópsias endometriais (em dias do ciclo), segundo o local avaliado e o tipo de infertilidade, estão contidos na Tabela 15. Não houve diferença na datação endometrial segundo o local avaliado e o tipo de infertilidade. 
Tabela 15: Resultados da datação (em dias) do endométrio segundo local de coleta e o tipo de infertilidade

\begin{tabular}{lccccccc}
\hline LOCAL/GRUPO & N & Média & DP & Mínimo & Máximo & Mediana & P \\
\hline PP Masculino & 5 & 17,0 & 3,8 & 11,0 & 21,0 & 18,0 & \\
Endometriose & 5 & 17,6 & 2,6 & 13,0 & 19,0 & 19,0 & $\mathbf{0 , 8 8}$ \\
DIP & 8 & 17,8 & 2,1 & 13,0 & 20,0 & 18,0 & \\
Controle & 6 & 18,3 & 1,0 & 17,0 & 20,0 & 18,0 & \\
PA Masculino & 5 & 16,4 & 3,7 & 11,0 & 20,0 & 18,0 & \\
Endometriose & 5 & 16,4 & 3,7 & 13,0 & 21,0 & 14,0 & $\mathbf{0 , 6 2}$ \\
DIP & 8 & 19,0 & 1,6 & 16,0 & 21,0 & 19,5 & \\
Controle & 5 & 18,8 & 1,3 & 17,0 & 20,0 & 19,0 & \\
ASP Masculino & 5 & 19,2 & 1,9 & 17,0 & 22,0 & 19,0 & \\
Endometriose & 5 & 18,6 & 4,1 & 12,0 & 23,0 & 20,0 & $\mathbf{0 , 5 3}$ \\
DIP & 8 & 18,8 & 2,5 & 16,0 & 23,0 & 18,0 & \\
Controle & 6 & 19,6 & 2,3 & 17,0 & 23,0 & 19,0 & \\
\hline
\end{tabular}

parede anterior (PA), parede posterior (PP), e aspirativa (ASP)

DIP- fator tuboperitoneal

A homogeneidade da datação endometrial foi avaliada em cada caso segundo os critérios histológicos de Noyes. O caso que teve ao menos um fragmento de endométrio em uma das biópsias com características distintas da fase lútea foi considerado heterogêneo. Foram homogêneos todos os controles férteis (6 pacientes) e $13(65 \%)$ dos casos inférteis. A avaliação da homogeneidade dos casos férteis e dos subgrupos inférteis está contida na Tabela 16. O grupo infértil apresentou maior número de casos com heterogeneidade endometrial, mas não houve significância estatística desta distribuição. 
Tabela 16: Homogeneidade na datação de fase menstrual no grupo controle e subgrupos inférteis, critérios histológicos de Noyes.

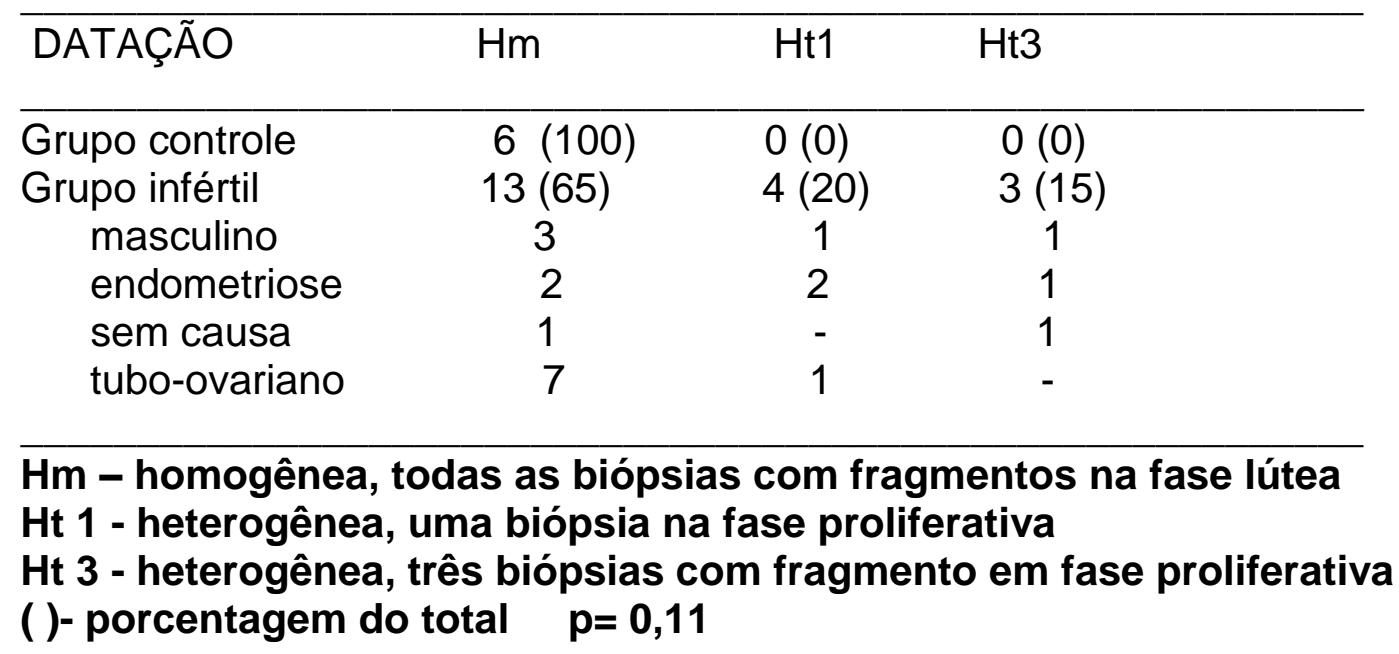

Biópsias em fase proliferativa, categorizadas como heterogêneas, ocorreram em $12(46,1 \%)$ das 26 amostras aspirativas, o que não foi observado em nenhuma das 11 biópsias dirigidas à parede posterior e que contavam com mais de um fragmento. A heterogeneidade foi observada em um caso $(13,7 \%)$ dentre 13 que tiveram mais de um fragmento coletado nas biópsias dirigidas à parede anterior $(p<0,01)$.

\subsection{3- Endometrite}

Foram detectados sinais de endometrite - infiltração do endométrio por plasmócitos em dois casos do estudo, detectados em pacientes do grupo infértil (10\%). Estas pacientes apresentavam infertilidade de causa tuboperitoneal, possível sequela de doença inflamatória pélvica (MIPA). O achado histológico ocorreu em 2,5\% do total de biópsias (uma aspirativa e outra da parede anterior). 


\subsection{4- Hemorragia}

As biópsias aspirativas apresentavam hemorragia no estroma em 18 amostras $(69,2 \%)$ das amostras, enquanto este fato não foi verificado em nenhum caso de biópsia dirigida.

\section{5- Discussão}

\section{1- Os métodos de avaliação endometrial}

No presente estudo foram comparados dois métodos para avaliação endometrial - a biópsia aspirativa, e a biópsia dirigida para o estudo de pacientes férteis e inférteis durante a janela de implantação. A biópsia endometrial dirigida através da histeroscopia é a técnica consagrada para o estudo de alterações focais do endométrio na suspeita de neoplasias. .A biópsia aspirativa do endométrio é o método padrão até o momento para 0 estudo do endométrio, dos genes e das proteínas relacionadas á implantação. Foi adotada a cânula de Pipelle para realização da biópsia aspirativa devido a relatos prévios de sua superioridade frente a outros instrumentos para biópsia endometrial às cegas apesar da falha desta modalidade de biópsia na identificação de lesões focais do endométrio (Bettocchi, Ceci et al., 2001; Bettocchi, Di Venere et al., 2002; Polena, Mergui et al., 2007; Williams, Brechin et al., 2008)

Em fase piloto da realização deste estudo foi constatado sangramento intracavitário à histeroscopia após a realização da biópsia aspirativa. Para contornar esse problema, realizamos em cada caso inicialmente as duas biópsias dirigidas, da parede anterior e posterior, e depois coletamos a amostra 
aspirativa. As duas técnicas foram adequadas para coletar amostras, pela quantidade e qualidade de material. A biópsia aspirativa possibilitou uma quantidade de tecido maior do que a obtida na biópsia dirigida - $100 \%$ de material abundante/moderado versus $90 \%$ de material moderado na dirigida. Porém a heterogeneidade da amostra, definida pela presença de pelo menos um fragmento que poderia ser datado de forma distinta, atingiu quase $50 \%$ na biópsia aspirativa frente a $0 \%$ das biópsias da parede posterior e $7,7 \%$ das biópsias da parede anterior. Os resultados obtidos na biópsia aspirativa foram superiores em relação à espessura do epitélio superficial, altura da célula na glândula endometrial e área circular da glândula frente às medidas obtidas nas biópsias dirigidas. Possivelmente o processo de aspiração promova uma distorção da arquitetura celular, o que pode interferir nas análises morfométricas de amostras obtidas por este método.

Outro aspecto observado no tecido endometrial obtido por biópsia aspirativa foi a presença de sangue no estroma do tecido endometrial, presente na maior parte das amostras, e ausente nas biópsias dirigidas. Considerado esse aspecto, deve-se atentar para possíveis distorções nos resultados de estudos que avaliam marcadores de implantação, que podem ser afetados pela contaminação por elementos celulares ou pertencentes ao plasma sanguíneo.

O presente estudo possibilitou a realização de biópsias dirigidas nas paredes anterior e posterior, o que não pode ser determinado ao certo na biópsia aspirativa, que é realizada às cegas. Esse aspecto tem particular interesse aos profissionais que atuam na reprodução humana, pois a implantação embrionária ocorre preferencialmente na parede posterior. Não observamos diferenças entre a parede anterior e posterior, quanto à espessura 
endometrial, altura das glândulas, e numero de glândulas por área, mas é possível que existam outros aspectos estruturais ou funcionais do tecido a serem investigados que possibilitem a implantação. As pesquisas endometriais através das biópsias dirigidas devem, em princípio, serem mais representativas para análise de pacientes férteis e inférteis, especialmente durante a janela de implantação.

5.2- $O$ endométrio da paciente fértil $X$ endométrio paciente infértil

\subsection{1- Aspectos morfométricos}

Entre os diversos critérios adotados para a análise morfométrica não foram encontradas diferenças significativas entre as pacientes férteis e inférteis. A amostra aspirativa mostrou diferença em relação às áreas obtidas das paredes anterior e posterior, mas isto deve ser creditado ao método de obtenção da amostra, pois foi semelhante ao observado no grupo controle. A técnica de biópsia que envolve sucção pode mascarar a correta leitura morfométrica. Os dados sugerem que a parede posterior (na sua porção fúndica) tende a ser semelhante do ponto de vista morfométrico à parede anterior no seu terço médio.

5.2.2- Aspectos anatomopatológicos- Devemos destacar que apenas as pacientes inférteis (35\%) apresentaram incongruência entre a datação de parte das amostras frente à fase do ciclo estimada (lútea). Este fato poderia determinar no endométrio uma menor superfície receptiva ao embrião, e causar uma dificuldade de implantação. Esta assincronia entre porções diferentes do 
endométrio foi relatada em biópsias aspirativas de pacientes com infertilidade tuboperitoneal por Edi-Osagie e colaboradores em 2004 (Edi-Osagie, Seif et al., 2004).

Foram detectados sinais sugestivos de endometrite em $25 \%$ das pacientes do grupo com fator tuboperitoneal de infertilidade. Estas pacientes eram assintomáticas. Através de exame histeroscópico e com biópsia aspirativa Polisseni e colaboradores em 2003 encontraram uma incidência de endometrite crônica em $12 \%$ das pacientes inférteis, e uma baixa acurácia para o diagnóstico visual (Polisseni, Bambirra et al., 2003). Outro estudo publicado em 2010 relata incidência de $30 \%$ de endometrite através de análise imunohistoquímica em pacientes com repetidas falhas de implantação (Johnston-Macananny, Hartnett et al., 2010). Após o tratamento houve melhora nas taxas de implantação deste estudo, porém persistia a redução frente ao grupo sem endometrite (Johnston-Macananny, Hartnett et al., 2010). Nossa incidência de endometrite pode estar subestimada devido à limitação da detecção dos plasmócitos sem a utilização de imunohistoquímica. Os resultados verificados contribuem para sugerir a realização de biópsia endometrial nas pacientes com infertilidade de causa tuboperitoneal como sequela de doença inflamatória pélvica.

\section{3 - A fase do ciclo da avaliação endometrial}

A determinação do período ovulatório através de ultrassonografia transvaginal seriada tem se mostrado o método mais confiável para acompanhamento da ovulação em pacientes ambulatoriais, com $96 \%$ de 
acerto. A curva de temperatura basal tem inadequada sensibilidade, $23 \%$ dos casos, e 90,3\% de especificidade, e os testes urinários de LH tem cerca de 80\% de sensibilidade (Shoupe, Mishell et al., 1989; Mcgovern, Myers et al., 2004). Outra possibilidade seria realizar a dosagem seriada de LH sérico, para avaliar a ovulação, mas a necessidade de deslocamento diário ao hospital inviabilizaria a participação de muitas pacientes que fizeram parte deste estudo; o método apresentou margem de erro superior ao da ultrassonografia em estudo comparativo (Shoupe, Mishell et al., 1989). A datação endometrial em nosso estudo demonstrou que as pacientes estavam na data correta para realização da biópsia. Houve concordância de 93,5\% na datação endometrial e nos $6,5 \%$ dos casos discordantes (cinco pacientes) esta diferença era de um dia e não alterou a fase do ciclo em que a paciente se encontrava. Este dado corrobora estudos prévios da literatura de grande concordância (aproximadamente 90\%) entre patologistas na datação da fase do ciclo

menstrual, principalmente em pacientes férteis (Myers, Silva et al., 2004). A avaliação ultrassonográfica da ovulação e a datação endometrial pelos patologistas foram ratificadas como métodos adequados para o estudo do endométrio na fase lútea, em casos individuais e nas amostras para pesquisa.

\section{4 - Tamanho da amostra}

A análise estatística mostrou que os dois grupos avaliados- fértil e controle, não diferiram quanto à idade, duração do ciclo menstrual e intervalo entre a menstruação e o dia da realização da histeroscopia.

Devido à escassez de estudos prévios que envolvem este tema não era possível um cálculo amostral prévio, porém o cálculo do poder do teste sempre 
superior a 95\% entre os achados encontrados permitiu afirmar que a casuística empregada foi suficiente para analisar os achados descritos. A ampliação da casuística e a repetição do estudo, poderão elucidar a ocorrência de heterogeneidade endometrial na região de coleta da biópsia aspirativa de pacientes inférteis.

\section{5- Perspectivas}

A infertilidade é uma situação clínica que envolve parcela significativa da população com consequências que extrapolam o âmbito conjugal e afetam toda a sociedade. No que tange à implantação, momento chave para se conseguir uma gestação, mesmo quando se utiliza a FIV associada às técnicas de diagnóstico pré implantacional não ultrapassamos a faixa dos 70\% de sucesso. A barreira para se atingir uma taxa de êxito mais elevada pode estar, em parte, no endométrio. A padronização dos métodos e técnicas de pesquisa é fundamental no avanço da investigação deste local. 


\section{6- Conclusões}

6.1- Foram determinadas através de biópsia endometrial dirigida padrões morfométricos para o endométrio na fase lútea de mulheres férteis e inférteis.

6.2- Não houve diferença morfométrica entre pacientes férteis e inférteis.

6.3- Houve diferença à morfometria e na análise histológica das amostras endometriais obtidas por biópsia aspirativa, frente às obtidas por biópsias dirigidas da parede uterina anterior e posterior.

6.4- Houve heterogeneidade na datação endometrial das biópsias obtidas por aspiração frente às dirigidas, predominantemente nas pacientes inférteis.

6.5- Os estudos endometriais podem ser realizados através de biópsia dirigida devido à quantidade de material adequado da amostra, maior homogeneidade e mínima contaminação por sangue.

6.6- Parte dos casos de infertilidade pode beneficiar-se da realização de histeroscopia e complementação por biópsia. 


\section{7- Bibliografia}

AARTS, J. W. et al. How patient-centred care relates to patients' quality of life and distress: a study in 427 women experiencing infertility. Hum Reprod, v. 27, n. 2, p. 488-95, Feb 2012. ISSN 1460-2350. Disponível em: < http://www.ncbi.nlm.nih.gov/pubmed/22108249 >.

ARTACHO-PERULA, E. et al. Morphometry and discriminant analysis of the endometrium. Anal Quant Cytol Histol, v. 14, n. 4, p. 320-9, Aug 1992. ISSN 0884-6812 (Print)0884-6812 (Linking). Disponível em: < http://www.ncbi.nlm.nih.gov/pubmed/1388569?dopt=Citation >.

. Histomorphometry of normal and abnormal endometrial samples. Int $\mathbf{J}$ Gynecol Pathol, v. 12, n. 2, p. 173-9, Apr 1993. ISSN 0277-1691 (Print)02771691 (Linking).

Disponível em:

http://www.ncbi.nlm.nih.gov/pubmed/8463042?dopt=Citation >.

BALASCH, J. Investigation of the infertile couple: investigation of the infertile couple in the era of assisted reproductive technology: a time for reappraisal. Hum Reprod, v. 15, n. 11, p. 2251-7, Nov 2000. ISSN 0268-1161. Disponível em: < http://www.ncbi.nlm.nih.gov/pubmed/11056115 >.

BETTOCCHI, S. New Era of Office Hysteroscopy. J Am Assoc Gynecol Laparosc, v. 3, n. 4, Supplement, p. S4, Aug 1996. ISSN 1074-3804. Disponível em: < http://www.ncbi.nlm.nih.gov/pubmed/9074084 >.

BETTOCCHI, S. et al. Diagnostic inadequacy of dilatation and curettage. Fertil Steril, v. 75, n. 4, p. 803-5, Apr 2001. ISSN 0015-0282. Disponível em: < http://www.ncbi.nlm.nih.gov/pubmed/11287038 >. 
- Endometrial biopsies using small-diameter hysteroscopes and 5F instruments: how can we obtain enough material for a correct histologic diagnosis? J Am Assoc Gynecol Laparosc, v. 9, n. 3, p. 290-2, Aug 2002. ISSN 1074-3804. Disponível em: < http://www.ncbi.nlm.nih.gov/pubmed/12101324 >.

$\mathrm{CECl}, \mathrm{O}$. et al. Comparison of hysteroscopic and hysterectomy findings for assessing the diagnostic accuracy of office hysteroscopy. Fertil Steril, v. 78, n. 3, p. 628-31, Sep 2002. ISSN 0015-0282. Disponível em: < http://www.ncbi.nlm.nih.gov/pubmed/12215345 >.

CHACHAMOVICH, J. L. et al. Psychological distress as predictor of quality of life in men experiencing infertility: a cross-sectional survey. Reprod Health, v. 7, p. 3, 2010. ISSN 1742-4755. Disponível em: < http://www.ncbi.nlm.nih.gov/pubmed/20459694 >.

CHACHAMOVICH, J. R. et al. Investigating quality of life and health-related quality of life in infertility: a systematic review. J Psychosom Obstet Gynaecol, v. 31, n. 2, p. 101-10, Jun 2010. ISSN 1743-8942. Disponível em: < http://www.ncbi.nlm.nih.gov/pubmed/20443659 >.

Agreement on perceptions of quality of life in couples dealing with infertility. J Obstet Gynecol Neonatal Nurs, v. 39, n. 5, p. 557-65, 2010 SepOct 2010. ISSN 1552-6909. Disponível em: < http://www.ncbi.nlm.nih.gov/pubmed/20920002 >.

CONNOLLY, M. et al. Assessing long-run economic benefits attributed to an IVF-conceived singleton based on projected lifetime net tax contributions in the UK. Hum Reprod, v. 24, n. 3, p. 626-32, Mar 2009. ISSN 1460-2350. Disponível em: < http://www.ncbi.nlm.nih.gov/pubmed/19056775 >.

CONNOLLY, M. P. et al. Long-term economic benefits attributed to IVFconceived children: a lifetime tax calculation. Am J Manag Care, v. 14, n. 9, p. 
598-604, Sep 2008. ISSN 1936-2692. Disponível em: < http://www.ncbi.nlm.nih.gov/pubmed/18778175 >.

CROSIGNANI, P. G.; RUBIN, B. L. Optimal use of infertility diagnostic tests and treatments. The ESHRE Capri Workshop Group. Hum Reprod, v. 15, n. 3, p. 723-32, Mar 2000. ISSN 0268-1161. Disponível em: < http://www.ncbi.nlm.nih.gov/pubmed/10686227 >.

EDI-OSAGIE, E. C. et al. Characterizing the endometrium in unexplained and tubal factor infertility: a multiparametric investigation. Fertil Steril, v. 82, n. 5, p. 1379-89, Nov 2004. ISSN 0015-0282. Disponível em: < http://www.ncbi.nlm.nih.gov/pubmed/15533364 >.

FARRELL, T. et al. The significance of an 'insufficient' Pipelle sample in the investigation of post-menopausal bleeding. Acta Obstet Gynecol Scand, v. 78, n. 9, p. 810-2, Oct 1999. ISSN 0001-6349. Disponível em: < http://www.ncbi.nlm.nih.gov/pubmed/10535347 >.

FATEMI, H. M. The luteal phase after 3 decades of IVF: what do we know? Reprod Biomed Online, v. 19 Suppl 4, p. 4331, 2009. ISSN 1472-6491 (Electronic)1472-6483 (Linking). Disponível em: < http://www.ncbi.nlm.nih.gov/pubmed/20034417?dopt=Citation >.

FRITZ, M. A. Clinical gynecologic endocrinology and infertility. 8th. Lippincot Williams \& Wilkins, 2011.

GEMZELL, C. A.; DICZFALUSY, E.; TILLINGER, G. Clinical effect of human pituitary follicle-stimulating hormone (FSH). J Clin Endocrinol Metab, v. 18, n. 12, p. 1333-48, Dec 1958. ISSN 0021-972X. Disponível em: < http://www.ncbi.nlm.nih.gov/pubmed/13611018 >. 
GUTIERREZ-MATEO, C. et al. Validation of microarray comparative genomic hybridization for comprehensive chromosome analysis of embryos. Fertil Steril, v. 95, n. 3, p. 953-8, Mar 1 2011. ISSN 1556-5653 (Electronic)0015-0282 (Linking). em:

http://www.ncbi.nlm.nih.gov/pubmed/20971462?dopt=Citation >.

JOHNSTON-MACANANNY, E. B. et al. Chronic endometritis is a frequent finding in women with recurrent implantation failure after in vitro fertilization. Fertil Steril, v. 93, n. 2, p. 437-41, Feb 2010. ISSN 1556-5653 (Electronic)0015-0282 (Linking). Disponível em:

http://www.ncbi.nlm.nih.gov/pubmed/19217098?dopt=Citation >.

KASIUS, J. C. et al. The reliability of the histological diagnosis of endometritis in asymptomatic IVF cases: a multicenter observer study. Hum Reprod, v. 27, n. 1, p. 153-8, Jan 2012. ISSN 1460-2350 (Electronic)0268-1161 (Linking). Disponível em: < http://www.ncbi.nlm.nih.gov/pubmed/22025228?dopt=Citation $>$.

KIRKMAN, M. Thinking of something to say: public and private narratives of infertility. Health Care Women Int, v. 22, n. 6, p. 523-35, Sep 2001. ISSN 0739-9332. Disponível em: < http://www.ncbi.nlm.nih.gov/pubmed/12141845 >.

KRÖGER, G. B.; EJZENBERG, D. The fiscal outcome of artificial conception in Brazil--creating citizens in developing countries. Hum Reprod, v. 27, n. 1, p. 142-5, Jan 2012. ISSN 1460-2350. Disponível em: < http://www.ncbi.nlm.nih.gov/pubmed/22068637 >.

KULAY JÚNIOR, L. et al. [Effect of different doses of 1-isopropylamine-3-(1naphthyloxy-2-propanol on total lipids of maternal plasma and hepatocytes of pregnant rats and their offspring subjected to acute stress induced by formaldehyde: histological, histochemical and biochemical study]. Rev Paul Med, v. 96, n. 1-2, p. 1-4, 1980 Jul-Aug 1980. ISSN 0035-0362. Disponível em: < http://www.ncbi.nlm.nih.gov/pubmed/7209264 >. 
LESSEY, B. A. Assessment of endometrial receptivity. Fertil Steril, v. 96, n. 3, p. 522-9, Sep 2011. ISSN 1556-5653 (Electronic)0015-0282 (Linking). Disponível em: < http://www.ncbi.nlm.nih.gov/pubmed/21880273?dopt=Citation $>$.

LOVERRO, G. et al. Diagnostic accuracy of hysteroscopy in endometrial hyperplasia. Maturitas, v. 25, n. 3, p. 187-91, Nov 1996. ISSN 0378-5122. Disponível em: < http://www.ncbi.nlm.nih.gov/pubmed/8981335 >.

MCGOVERN, P. G. et al. Absence of secretory endometrium after falsepositive home urine luteinizing hormone testing. Fertil Steril, v. 82, n. 5, p. 1273-7, Nov 2004. ISSN 0015-0282 (Print)0015-0282 (Linking). Disponível em: < http://www.ncbi.nlm.nih.gov/pubmed/15533341?dopt=Citation >.

MYERS, E. R. et al. Interobserver and intraobserver variability in the histological dating of the endometrium in fertile and infertile women. Fertil Steril, v. 82, n. 5, p. 1278-82, Nov 2004. ISSN 0015-0282. Disponível em: < http://www.ncbi.nlm.nih.gov/pubmed/15533342 >.

NOYES, R. W.; HERTIG, A. T.; ROCK, J. Dating the endometrial biopsy. Am J Obstet Gynecol, v. 122, n. 2, p. 262-3, May 1975. ISSN 0002-9378 (Print)0002-9378 (Linking). Disponível em: < http://www.ncbi.nlm.nih.gov/pubmed/1155504?dopt=Citation >.

PINBORG, A.; LOFT, A.; NYBOE ANDERSEN, A. Neonatal outcome in a Danish national cohort of 8602 children born after in vitro fertilization or intracytoplasmic sperm injection: the role of twin pregnancy. Acta Obstet Gynecol Scand, v. 83, n. 11, p. 1071-8, Nov 2004. ISSN 0001-6349. Disponível em: < http://www.ncbi.nlm.nih.gov/pubmed/15488125 >.

POLENA, V. et al. The role of Pipelle Mark II sampling in endometrial disease diagnosis. Eur J Obstet Gynecol Reprod Biol, v. 134, n. 2, p. 233-7, Oct 2007. ISSN 0301-2115. Disponível em: < http://www.ncbi.nlm.nih.gov/pubmed/17029754 >. 
POLISSENI, F.; BAMBIRRA, E. A.; CAMARGOS, A. F. Detection of chronic endometritis by diagnostic hysteroscopy in asymptomatic infertile patients. Gynecol Obstet Invest, v. 55, n. 4, p. 205-10, 2003. ISSN 0378-7346 (Print)0378-7346 (Linking).

Disponível em: http://www.ncbi.nlm.nih.gov/pubmed/12904693?dopt=Citation >.

REVEL, A. Defective endometrial receptivity. Fertil Steril, v. 97, n. 5, p. 102832, May 2012. ISSN 1556-5653 (Electronic)0015-0282 (Linking). Disponível em: < http://www.ncbi.nlm.nih.gov/pubmed/22542142?dopt=Citation >.

ROBINSON, B. E. Birds do it. Bees do it. So why not single women and lesbians? Bioethics, v. 11, n. 3-4, p. 217-27, 1997 Jul-Oct 1997. ISSN 02699702. Disponível em: < http://www.ncbi.nlm.nih.gov/pubmed/11654775 >.

ROCK, J.; BARTLETT, M. K. Biopsy studies of human endometrium: criteria of dating and information about amenorrhea, menorrhagia, and time of ovulation. $\mathbf{J}$ Am Med Assoc, v. 108, n. 24, p. 2022-8, Jun 1937. ISSN 0002-9955. Disponível em: < http://www.ncbi.nlm.nih.gov/pubmed/12255649 >.

ROGERS, P. A.; MURPHY, C. R. Morphometric and freeze fracture studies of human endometrium during the peri-implantation period. Reprod Fertil Dev, v. 4, n. 3, p. 265-9, 1992. ISSN 1031-3613 (Print)1031-3613 (Linking). Disponível em: < http://www.ncbi.nlm.nih.gov/pubmed/1438956?dopt=Citation >.

ROGERS, P. A. et al. Correlation of endometrial histology, morphometry, and ultrasound appearance after different stimulation protocols for in vitro fertilization. Fertil Steril, v. 55, n. 3, p. 583-7, Mar 1991. ISSN 0015-0282 (Print)0015-0282 (Linking). Disponível em: < http://www.ncbi.nlm.nih.gov/pubmed/1900484?dopt=Citation >.

RUTSTEIN, S. O. Infecundity, Infertility, and Childlessness in Developing Countries DHS Comparative Reports No. 9. SHAH, I. H.: ORC Macro and the World Health Organization. 2004. 
SCHMIDT, L. et al. Demographic and medical consequences of the postponement of parenthood. Hum Reprod Update, v. 18, n. 1, p. 29-43, Jan 2012. ISSN 1460-2369.

Disponível em:

http://www.ncbi.nlm.nih.gov/pubmed/21989171 >.

SERAFINI, P. C. et al. Endometrial claudin-4 and leukemia inhibitory factor are associated with assisted reproduction outcome. Reprod Biol Endocrinol, v. 7, p. 30, 2009. ISSN 1477-7827. Disponível em: < http://www.ncbi.nlm.nih.gov/pubmed/19374770 >.

SHOUPE, D. et al. Correlation of endometrial maturation with four methods of estimating day of ovulation. Obstet Gynecol, v. 73, n. 1, p. 88-92, Jan 1989. ISSN 0029-7844 (Print)0029-7844 (Linking). Disponível em: < http://www.ncbi.nlm.nih.gov/pubmed/2642330?dopt=Citation >.

SIMPSON, J. L. Preimplantation genetic diagnosis at 20 years. Prenat Diagn, v. 30, n. 7, p. 682-95, Jul 2010. ISSN 1097-0223 (Electronic)0197-3851 (Linking). em:

http://www.ncbi.nlm.nih.gov/pubmed/20572111?dopt=Citation >.

STEPTOE, P. C.; EDWARDS, R. G. Birth after the reimplantation of a human embryo. Lancet, v. 2, n. 8085, p. 366, Aug 1978. ISSN 0140-6736. Disponível em: < http://www.ncbi.nlm.nih.gov/pubmed/79723 >.

VAN VOORHIS, B. J. Outcomes from assisted reproductive technology. Obstet Gynecol, v. 107, n. 1, p. 183-200, Jan 2006. ISSN 0029-7844. Disponível em: $<$ http://www.ncbi.nlm.nih.gov/pubmed/16394060 >.

WHO | Mother or nothing: the agony of infertility. Bull World Health Organ: World Health Organization. 88: 881-2 p. 2010. 
WILLIAMS, A. R. et al. Factors affecting adequacy of Pipelle and Tao Brush endometrial sampling. BJOG, v. 115, n. 8, p. 1028-36, Jul 2008. ISSN 14710528. Disponível em: < http://www.ncbi.nlm.nih.gov/pubmed/18651884 >.

YLI-KUHA, A. N. et al. Cancer morbidity in a cohort of 9175 Finnish women treated for infertility. Hum Reprod, v. 27, n. 4, p. 1149-55, Apr 2012. ISSN 1460-2350. Disponível em: < http://www.ncbi.nlm.nih.gov/pubmed/22343550 >.

ZANATTA, A. et al. The role of the Hoxa10/HOXA10 gene in the etiology of endometriosis and its related infertility: a review. J Assist Reprod Genet, v. 27, n. 12, p. 701-10, Dec 2010. ISSN 1573-7330. Disponível em: < http://www.ncbi.nlm.nih.gov/pubmed/20821045 >.

ZEGERS-HOCHSCHILD, F. et al. The International Committee for Monitoring Assisted Reproductive Technology (ICMART) and the World Health Organization (WHO) Revised Glossary on ART Terminology, 2009. Hum Reprod, v. 24, n. 11, p. 2683-7, Nov 2009. ISSN 1460-2350. Disponível em: < http://www.ncbi.nlm.nih.gov/pubmed/19801627 >.

. The ICMART glossary on ART terminology. Hum Reprod, v. 21, n. 8, p. 1968-70, Aug 2006. ISSN 0268-1161. Disponível em: < http://www.ncbi.nlm.nih.gov/pubmed/16864610 >. 


\section{8- Anexos}

Anexo A - Figuras complementares

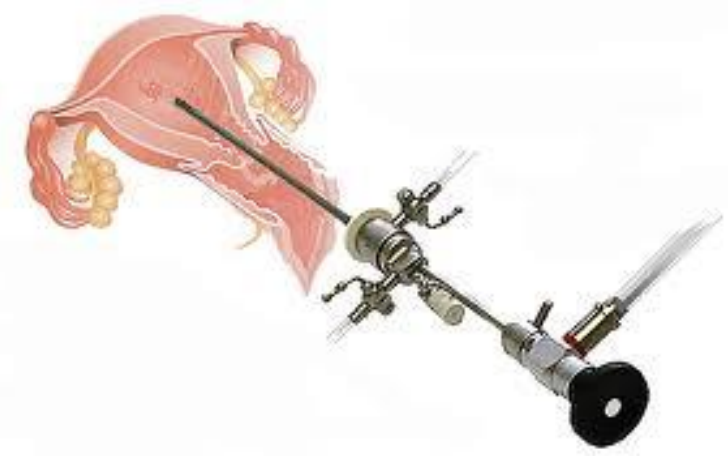

Fonte: site Whittemore Enterprises

Figura 2- Esquema para ilustrar a histeroscopia diagnóstica com equipamento de Bettocchi ${ }^{\circledR}$

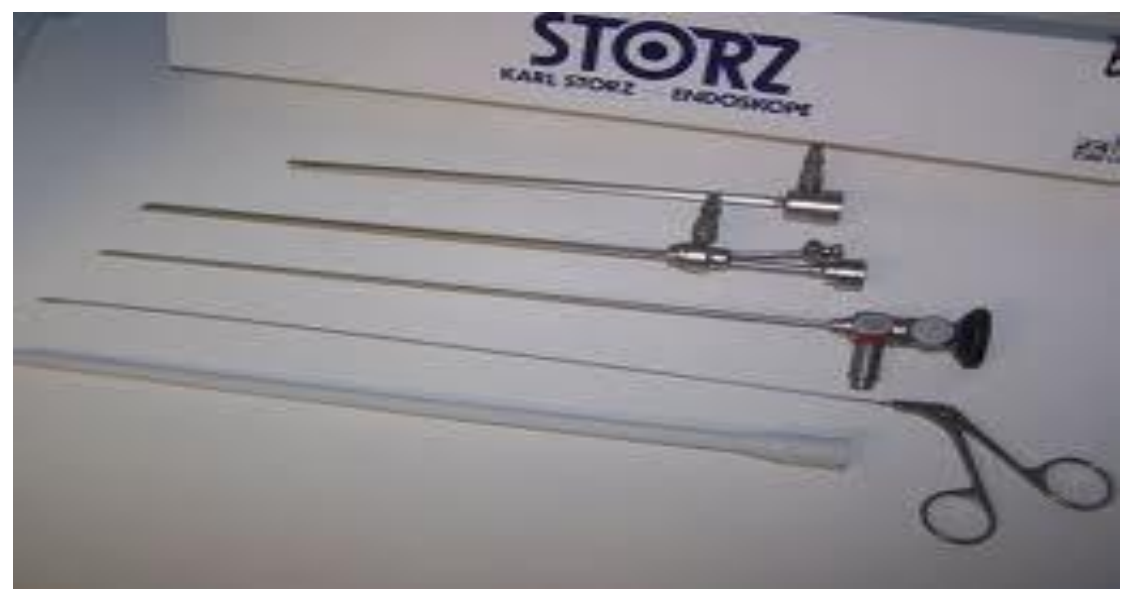

Fonte: site Storz

Figura 3- Instrumental para histeroscopia diagnóstica com

Equipamento de Bettocchi® 


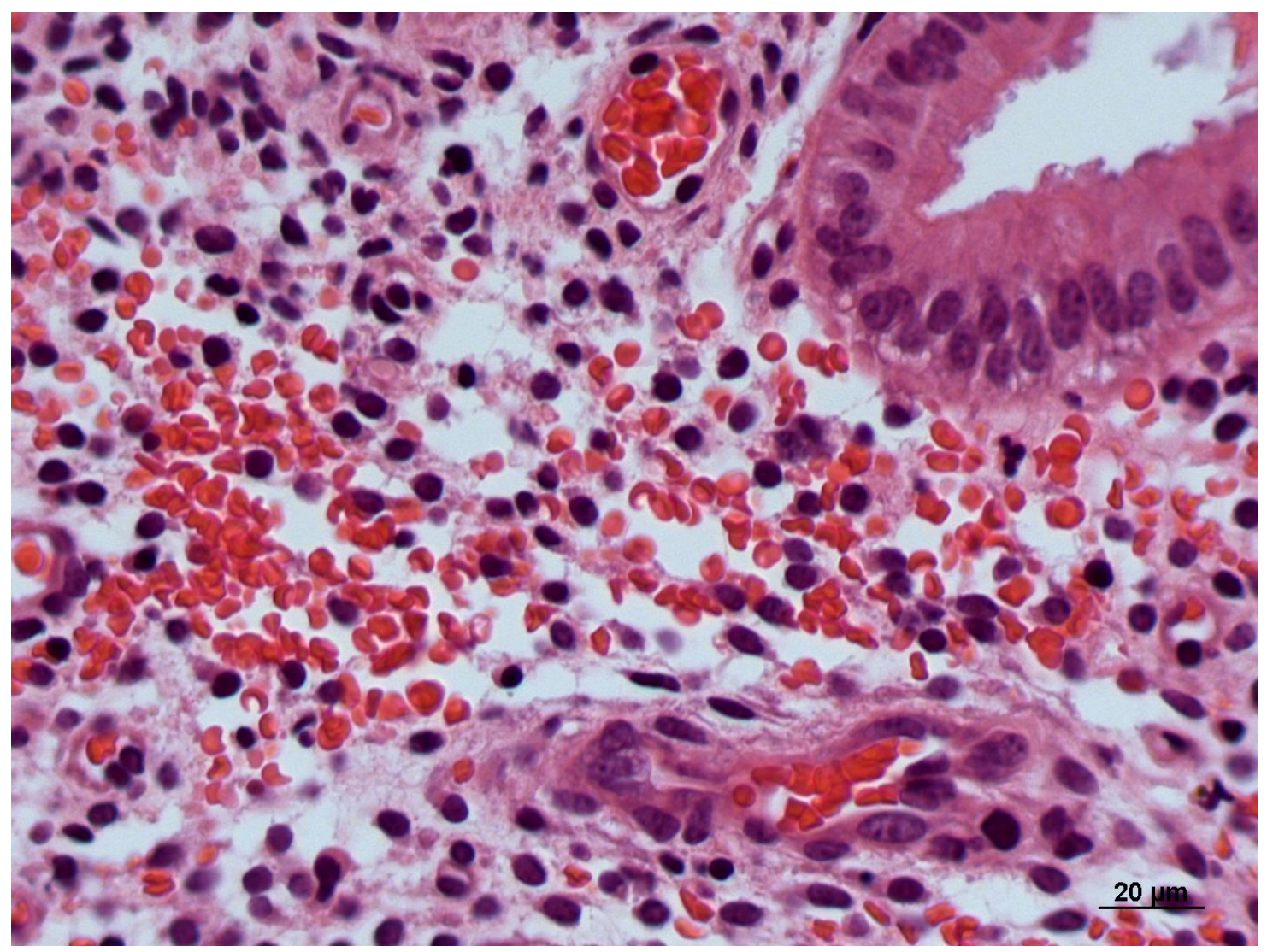

Figura 4- Imagem de biópsia aspirativa com hemorragia no estroma endometrial grupo controle fértil 

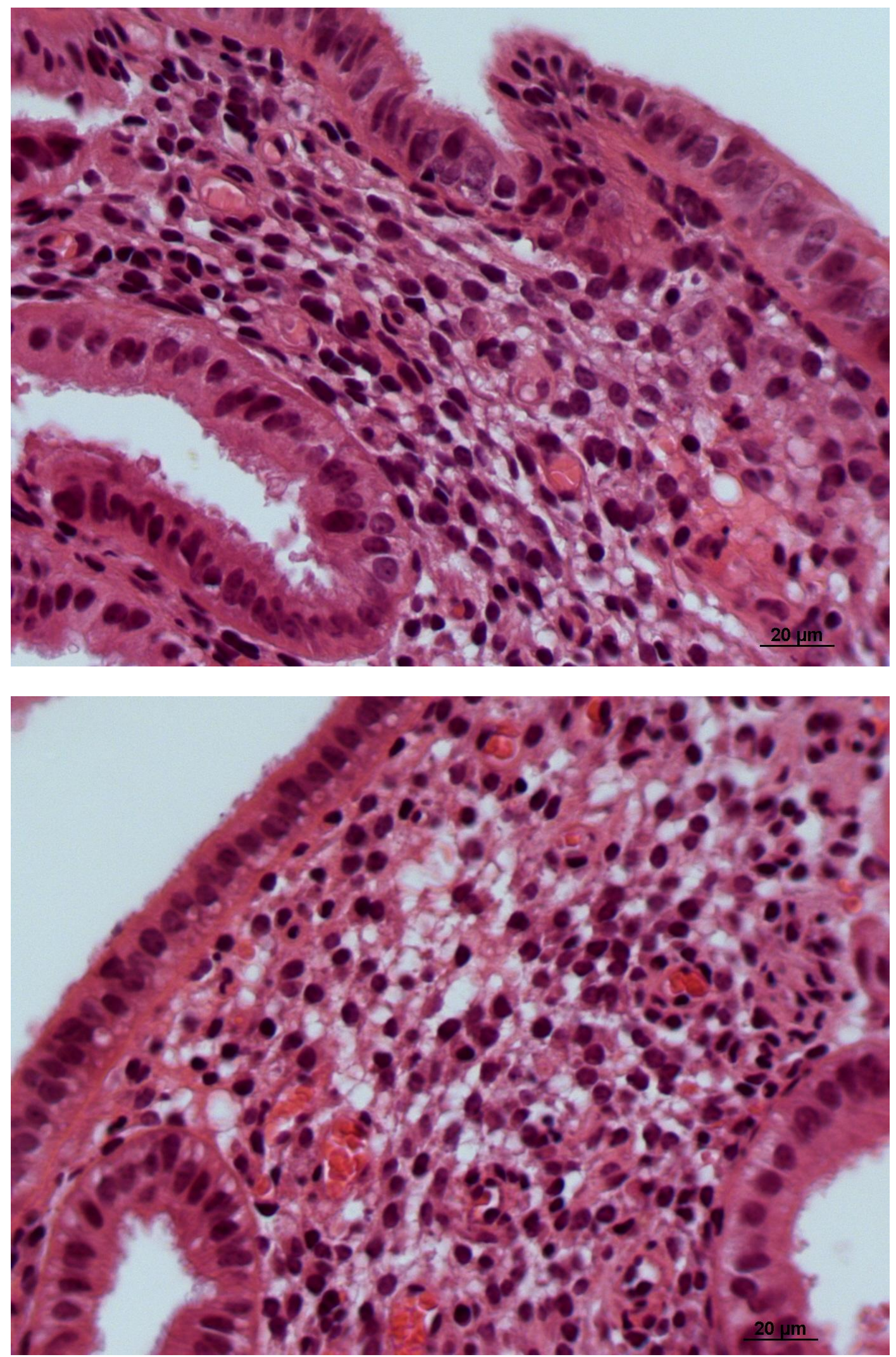

Figuras 5 e 6- Imagem de biópsia dirigida do grupo controle fértil com estroma preservado

Anexo B- TERMO DE CONSENTIMENTO LIVRE E ESCLARECIDO 
HOSPITAL DAS CLÍNICAS DA FACULDADE DE MEDICINA DA UNIVERSIDADE DE SÃO PAULO-HCFMUSP

TERMO DE CONSENTIMENTO LIVRE E ESCLARECIDO

DADOS DE IDENTIFICAÇÃO DO SUJEITO DA PESQUISA OU RESPONSÁVEL LEGAL

$1 . \quad$ NOME:

DOCUMENTO DE IDENTIDADE N :

SEXO : $\quad . M \square$ $\mathrm{F}$ 口

DATA NASCIMENTO: .......................

ENDEREÇO

APTO:

BAIRRO:

CIDADE

CEP:

TELEFONE: DDD

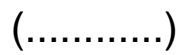

2.RESPONSÁVEL

LEGAL

NATUREZA (grau de parentesco, tutor, curador etc.)

DOCUMENTO DE IDENTIDADE SEXO: $M \square F \square$

DATA NASCIMENTO.: .....................

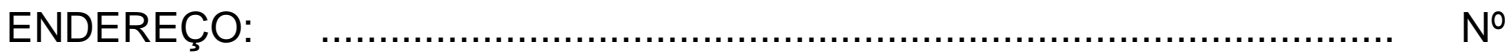

APTO:

BAIRRO:

CIDADE: 
CEP:

DADOS SOBRE A PESQUISA

1. TÍTULO DO PROTOCOLO DE PESQUISA Estudo histomorfológico e de receptividade endometrial na fase lútea de mulheres férteis e inférteis

PESQUISADOR: Dr. Dani Ejzenberg

CARGO/FUNÇÃO: Médico

INSCRIÇÃO CONSELHO REGIONAL № 100673.

UNIDADE DO HCFMUSP: Clínica Ginecológica-Departamento de Obstetrícia e Ginecologia

3. AVALIAÇÃO DO RISCO DA PESQUISA:

$\begin{array}{lll}\text { RISCO MÍNIMO } & x & \text { RISCO MÉDIO } \\ \text { RISCO BAIXO } & \square & \text { RISCO MAIOR }\end{array}$

\section{DURAÇÃO}

DA

PESQUISA

meses

1 - O objetivo desta pesquisa é o estudo de alterações na estrutura e na presença de proteínas presentes no endométrio (a porção interna do útero) que podem facilitar ou dificultar a gravidez. 2 -Será realizada uma endoscopia do útero em regime ambulatorial (histeroscopia) para avaliar a normalidade do útero internamente e a realização de biópsia para avaliação do endométrio. Durante o ciclo menstrual serão realizadas ultrasonografias para se confirmar o dia da ovulação e podem ser solitadas dosagens hormonais relacionadas com a fertilidade. 3- A endoscopia pode gerar cólica de pequena intensidade e risco mínimo de sangramento ou infecção 
4 -Trata-se de estudo experimental testando a hipótese de que a presença de determinadas alterações e proteínas dentro do útero pode influenciar no sucesso do tratamento da infertilidade

5-Em qualquer etapa do estudo, você terá acesso aos profissionais responsáveis pela pesquisa para esclarecimento de eventuais dúvidas. O principal investigador é o $\mathrm{Dr}$ Dani Ejzenberg que pode ser encontrado no endereço Av. Dr. Enéas de Carvalho Aguiar, 25510 andar setor de Reprodução Humana - Cerqueira César - 05403-000 / São Paulo - Brasil Telefone(s) 30696647 Se você tiver alguma consideração ou dúvida sobre a ética da pesquisa, entre em contato com o Comitê de Ética em Pesquisa (CEP) - Rua Ovídio Pires de Campos, 225 - 5o andar - tel: 3069-6442 ramais 16, 17, 18 ou 20, FAX: 3069-6442 ramal 26 - E-mail: cappesq@hcnet.usp.br 8 - É garantida a liberdade da retirada de consentimento a qualquer momento e deixar de participar do estudo, sem qualquer prejuízo à continuidade de seu tratamento na

Instituição; 09 - As informações obtidas serão analisadas em conjunto com outros pacientes, não sendo divulgado a identificação de nenhum paciente; 10 - É seu direito ser mantida atualizada sobre os resultados parciais das pesquisas, quando em estudos abertos ou de resultados que sejam do conhecimento dos pesquisadores; 11 - Não há despesas pessoais para o participante em qualquer fase do estudo, incluindo exames e consultas. Também não há compensação financeira relacionada à sua participação. Se existir qualquer despesa

adicional, ela será absorvida pelo orçamento da pesquisa. 12 - Em caso de dano pessoal, diretamente causado pelos procedimentos ou tratamentos propostos neste estudo (nexo causal comprovado), o participante tem direito a tratamento médico na Instituição, bem como às indenizações legalmente estabelecidas. 13 - Compromisso do pesquisador de utilizar os dados e o material coletado somente para esta pesquisa.

Acredito ter sido suficientemente informado a respeito das informações que li ou que foram lidas para mim, descrevendo o estudo"........................" Eu discuti com o Dr. Dani Ejzenberg. sobre a minha decisão em participar 
nesse estudo. Ficaram claros para mim quais são os propósitos do estudo, os procedimentos a serem realizados, seus desconfortos e riscos, as garantias de confidencialidade e de esclarecimentos permanentes. Ficou claro também que minha participação é isenta de despesas e que tenho garantia do acesso a tratamento hospitalar quando necessário. Concordo voluntariamente em participar deste estudo e poderei retirar o meu consentimento a qualquer momento, antes ou durante o mesmo, sem penalidades ou prejuízo ou perda de qualquer benefício que eu possa ter adquirido, ou no meu atendimento neste Serviço.

Assinatura do paciente/representante legal

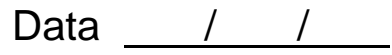

Assinatura da testemunha

Data 11

para casos de pacientes menores de 18 anos, analfabetos, semi-analfabetos ou portadores de deficiência auditiva ou visual.

(Somente para o responsável do projeto)

Declaro que obtive de forma apropriada e voluntária o Consentimento Livre e Esclarecido deste paciente ou representante legal para a participação neste estudo.

Assinatura do responsável pelo estudo Data 11 


\section{Anexo C- Aprovação do Comitê de Ética}

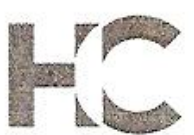

\section{APROVAÇĀO}

A Comissāo de Ética para Análise de Projetos de Pesquisa CAPpesq da Diretoria Clínica do Hospital das Clínicas e da Faculdade de Medicina da Universidade de São Paulo, em sessão de 17/06/2009, APROVOU ○ Protocolo de Pesquisa n 0144/09, intitulado: "ESTUdO HISTOMORFOLÓGICO E DE RECEPTIVIDADE ENDOMETRIAL NA FASE LÚTEA DE MULHERES FÉRTEIS E INFÉRTEIS " apresentado pelo Departamento de OBSTETŔ́CIA E GINECOLOGIA, inclusive O Termo de Consentimento Livre e Esclarecido.

Cabe ao pesquisador elaborar e apresentar à CAPPesq, os relatórios parciais e final sobre a pesquisa (Resolução do Conselho Nacional de Saúde $n^{\circ} 196$, de 10/10/1996, inciso IX.2, letra "c").

Pesquisador (a) Responsável: Prof. Dr. Edmund Chada Baracat

Pesquisador (a) Executante: Dani Ejzenberg

Co-orientador: Dr. Paulo César Serafini

CAPPesq, 19 de Junho de 2009

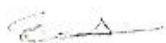

Prof. Dr. Eduardo Massad Presidente da Comissão de Ética para Análise de Projetos de Pesquisa

Comissão de Ética para Análise de Projetos de Pesquisa do HCFMUSP e da FMUSP Diretoria Clinica do Hospital das Clinicas da Faculdade de Medicina da Universidade de São Paulo Rua Ovídio Pires de Campos, 225, $5^{\circ}$ andar - CEP 05403010 - Săo Paulo - SP Fone: 01130696442 Fax. 01130696492 e-mail

cappesq@hcnet.usp.br / secretariacappesq2@hcnet.usp.br 